\title{
PIE on Five Irradiated AGR-1 Compacts
}

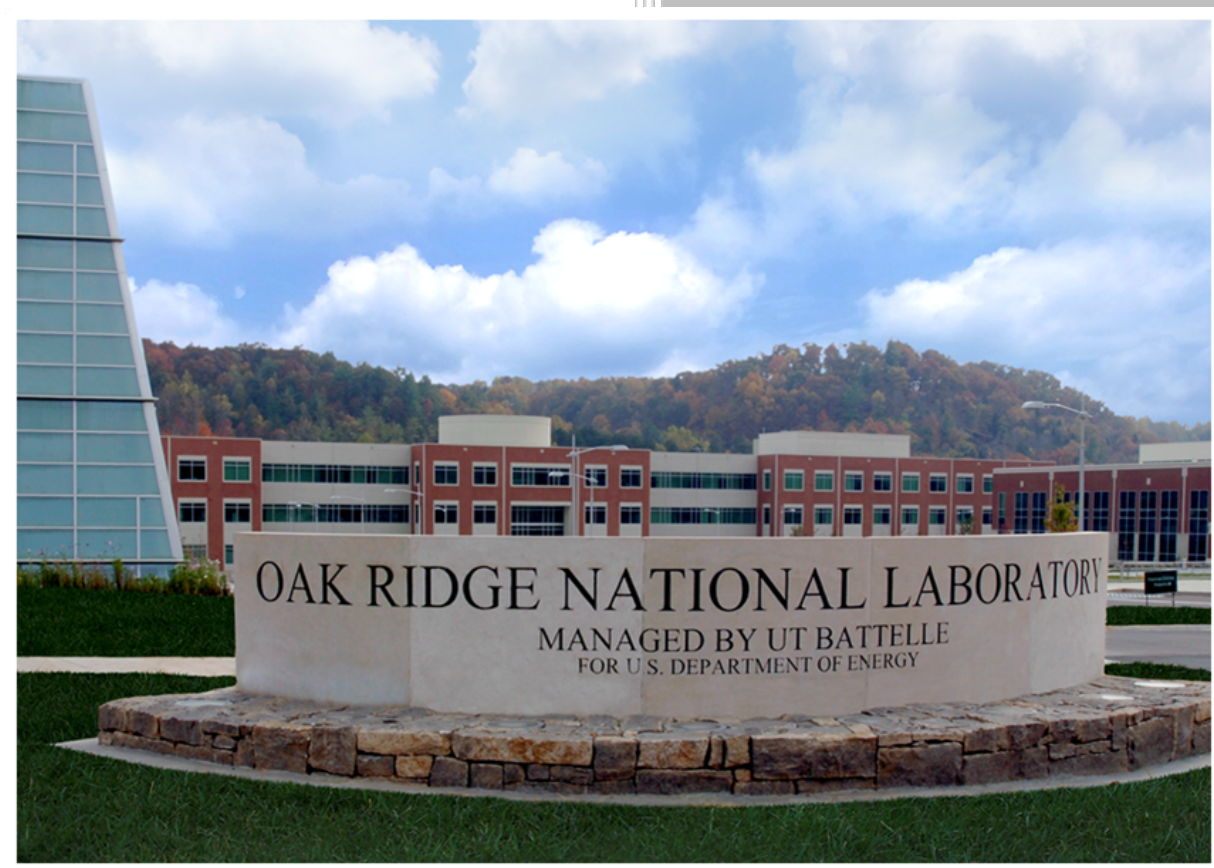

John Hunn

Robert Morris

Charles Baldwin

Fred Montgomery

Chinthaka Silva

September 2012 


\title{
DOCUMENT AVAILABILITY
}

Reports produced after January 1, 1996, are generally available free via US Department of Energy (DOE) SciTech Connect.

Website www.osti.gov

Reports produced before January 1, 1996, may be purchased by members of the public from the following source:

\author{
National Technical Information Service \\ 5285 Port Royal Road \\ Springfield, VA 22161 \\ Telephone 703-605-6000 (1-800-553-6847) \\ TDD 703-487-4639 \\ Fax 703-605-6900 \\ E-mail info@ntis.gov \\ Website http://classic.ntis.gov/
}

Reports are available to DOE employees, DOE contractors, Energy Technology Data Exchange representatives, and International Nuclear Information System representatives from the following source:

Office of Scientific and Technical Information

PO Box 62

Oak Ridge, TN 37831

Telephone 865-576-8401

Fax 865-576-5728

E-mail reports@osti.gov

Website http://www.osti.gov/contact.html

This report was prepared as an account of work sponsored by an
agency of the United States Government. Neither the United States
Government nor any agency thereof, nor any of their employees,
makes any warranty, express or implied, or assumes any legal liability
or responsibility for the accuracy, completeness, or usefulness of any
information, apparatus, product, or process disclosed, or represents
that its use would not infringe privately owned rights. Reference herein
to any specific commercial product, process, or service by trade name,
trademark, manufacturer, or otherwise, does not necessarily constitute
or imply its endorsement, recommendation, or favoring by the United
States Government or any agency thereof. The views and opinions of
authors expressed herein do not necessarily state or reflect those of
the United States Government or any agency thereof.


Advanced Gas Reactor (AGR) program

\title{
PIE on Five Irradiated AGR-1 Compacts
}

\author{
John Hunn \\ Robert Morris \\ Charles Baldwin \\ Fred Montgomery \\ Chinthaka Silva
}

Date Published:

September 2012

Prepared by

OAK RIDGE NATIONAL LABORATORY

Oak Ridge, TN 37831-6283

managed by

UT-BATTELLE, LLC

for the

US DEPARTMENT OF ENERGY

under contract DE-AC05-00OR22725 
ORNL/TM-2012/397

\section{PIE ON FIVE IRRADIATED AGR-1 COMPACTS}

\section{Summary}

Post-irradiation examination (PIE) is in progress on coated particle fuel compacts from the first Advanced Gas Reactor irradiation experiment (AGR-1). PIE has been completed on five compacts at the Oak Ridge National Laboratory (ORNL). Three compacts (Compacts 6-1-1, 4-4-2, and 5-2-3) were examined in the as-irradiated condition and two compacts (Compacts 6-4-3 and 3-3-2) were subjected to safety testing at $1600^{\circ} \mathrm{C}$, followed by post-safety testing examination similar to the PIE performed on the as-irradiated compacts. All compacts were subjected to a standard set of analyses that included the following: (1) detection of exposed fission products by Deconsolidation-Leach-Burn-Leach (DLBL), (2) measurement of gamma-emitting fission product inventory using the Irradiated Microsphere Gamma Analyzer (IMGA), and (3) microstructural examination by x-ray tomography and materialography. The equipment and methods used are reported in detail in ORNL/TM-2012/233, AGR-1 Irradiated Compact 6-1-1 PIE Report, and have been summarized in the next section of this report. This report also provides a brief summary of the results of the completed PIE. Preliminary trends are discussed in this report, but final conclusions will require the support of additional data and further analysis. A separate report is being generated for each AGR-1 compact after PIE is complete that describes in detail the examinations performed and fully documents the data obtained. A final AGR-1 PIE summary report will compile all available data and provide a more comprehensive analysis of the AGR-1 fuel performance.

In general, it was observed that the tristructural isotropic (TRISO) coated particles remained intact during irradiation and subsequent safety testing to $1600^{\circ} \mathrm{C}$. No significant gaseous ${ }^{85} \mathrm{Kr}$ release was detected during the irradiation or high temperature safety testing, which would be indicative of simultaneous failure of all three outer layers of the TRISO coating. Only three particles with defective $\mathrm{SiC}$ layers were detected in the five compacts included in this summary. These particles were detected because they released a significant fraction of their cesium inventory, which was generally well retained. Two particles from Compact 5-2-3 released cesium during irradiation and one particle from Compact 3-3-2 released cesium during safety testing. However, it is evident that some fission products were released through intact $\mathrm{SiC}$ during irradiation. Most of these fission products were trapped in the compact matrix, where they could be analyzed by PIE. In terms of fractional release, the main fission products detected outside intact $\mathrm{SiC}$ were silver, palladium, and europium.

The main impact of irradiation on the microstructure of the TRISO-coating layers was densification and shrinkage of the buffer layer, which often led to buffer fracture and subsequent enhanced swelling of the kernel. Some inner pyrocarbon (IPyC) layers were cracked by the radiation-induced changes in the buffer layer, and on rare occasion these cracks propagated into the SiC. In the two particles that released cesium during irradiation, these $\mathrm{SiC}$ cracks penetrated through the entire layer. The particle from Compact 3-3-2 that released cesium was not directly related to irradiation damage. Its $\mathrm{SiC}$ layer was determined to be porous as a result of a fabrication defect that occurs when a particle is over-fluidized in the coater, causing it to pick up carbon soot on the surface of the IPyC prior to $\mathrm{SiC}$ deposition. This porous SiC layer remained sufficiently intact during irradiation to retain cesium, but finally cracked during high temperature testing.

Analysis of fission products remaining in the coated particles showed that the retention of silver varied dramatically from particle-to-particle within each compact. Examination with the IMGA determined that some particles contained a level of ${ }^{110 \mathrm{~m}} \mathrm{Ag}$ equivalent to that calculated to have been generated over the three-year irradiation period, while other particles contained too little to be detected by the gamma analysis. The mechanism for silver release is still being investigated. Attempts to correlate the varied release behavior to obvious radiation-induced changes in the coating layers have not been successful. Scanning electron microscopy (SEM) has provided some evidence that particles with higher silver release also show greater penetration of palladium silicide into the $\mathrm{SiC}$ layer, and this should be studied further. 


\section{Standard Examination Procedure}

Compacts 6-1-1, 4-4-2, and 5-2-3 were examined in the as-irradiated state. Compacts were electrolytically deconsolidated in nitric acid to break up the matrix carbon and release the TRISO-coated particles from the compact. Particles and matrix residue were then leached twice with hot nitric acid in a Soxhlet extractor to dissolve uranium and any soluble fission products in the matrix residue or on the surface of the particles. This leaching step will also dissolve any exposed kernels from particles with fractured TRISO coatings.

After the deconsolidation-leach (DL), particles were separated from the matrix residue by first boiling in nitric acid to clean off any residual matrix from the outer surface of the TRISO particles, and then washing the matrix residue and acid through a sieve with $500-\mu \mathrm{m}$-square holes. The washed and dried particles were then transferred to the IMGA hot cell for sorting and gamma analysis. The matrix residue was dried and burned at $750^{\circ} \mathrm{C}$ to oxidize any remaining elements. Boiling nitric acid was then used to leach the ash. After IMGA examination, approximately $90 \%$ of the particles were returned to the Soxhlet thimble for burn-leach (BL). This final leaching step will detect any particles with through-wall defects in the $\mathrm{SiC}$ that were protected by intact pyrocarbon during the pre-burn leaching. The flow chart in Figure 1 outlines the DLBL process.

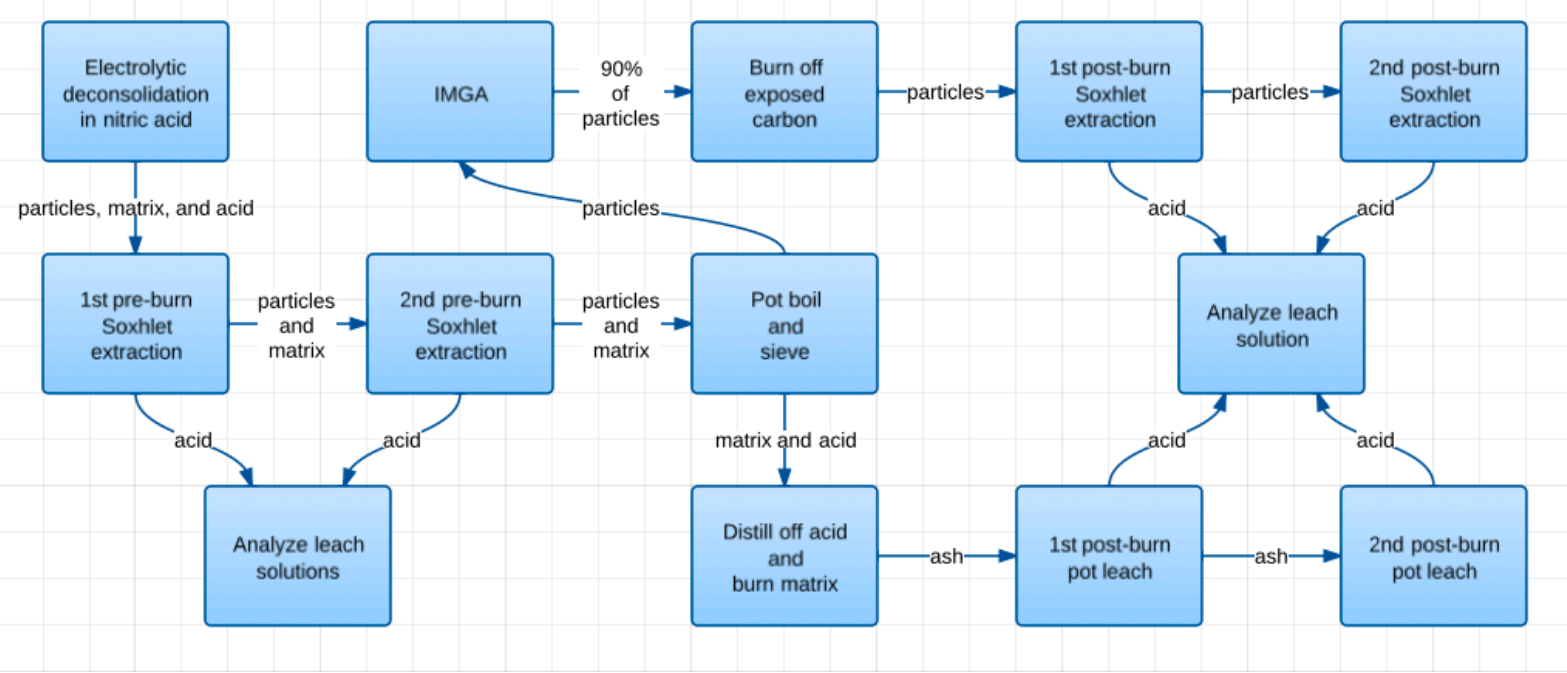

Figure 1. Flow chart of the DLBL process.

Particles extracted from the compacts by the deconsolidation-leach were surveyed for ${ }^{137} \mathrm{Cs}$ and ${ }^{144} \mathrm{Ce}$ inventory using the IMGA. The IMGA uses a computer-controlled pneumatic particle manipulator to remove individual particles from a hopper, transfer them to a gamma scanning station, and then sort them based on the measured gamma spectra. This process requires about two weeks to analyze and sort all $4100+$ particles from each compact using a scan time of 80-100 seconds. Particles were sorted according to their ${ }^{144} \mathrm{Ce}$ content, where particles with below average cerium inventory were placed in a separate receptacle for further analysis. Particles were also sorted by their ${ }^{137} \mathrm{Cs} /{ }^{144} \mathrm{Ce}$ ratio, again sorting particles with a low ratio into designated vials. Below average cerium content could indicate particles with abnormally small kernels or kernels that have been leached by the DL process. A low ${ }^{137} \mathrm{Cs} /{ }^{144} \mathrm{Ce}$ ratio implies particle have preferentially lost cesium, which generally indicates a through-wall defect in the $\mathrm{SiC}$ layer. After the initial IMGA survey, particles identified as having anomalous cerium or cesium inventory were surveyed for 4-6 hours to increase the accuracy of the gamma spectra and measure other lower activity gamma emitters. A random subset of 50-120 particles was also riffled from each compact to 
provide a representative sample for determination of the inventory distribution of key detectable isotopes, including ${ }^{95} \mathrm{Zr},{ }^{106} \mathrm{Ru},{ }^{110 \mathrm{~m}} \mathrm{Ag},{ }^{125} \mathrm{Sb},{ }^{134} \mathrm{Cs},{ }^{137} \mathrm{Cs},{ }^{144} \mathrm{Ce}$, and ${ }^{154} \mathrm{Eu}$.

After 4-6-hour IMGA scanning, particles were selected for microstructural analysis. Particles with anomalous fission product inventory were compared to average particles. Particular emphasis was given to particles that exhibited different silver retention to look for any related indicators. Microstructural analysis included x-ray imaging and mechanical polishing, followed by analysis using optical and scanning electron microscopes.

Three-dimensional microstructural analysis was achieved using a high-resolution x-ray tomography system specially designed for coated particle fuel imaging. This system can image coating structure with resolution close to $1 \mu \mathrm{m}$, and has been used during AGR-1 fuel development to characterize and understand defect structures in a manner not previously available. A shielded container was designed for mounting irradiated particles on the $\mathrm{x}$-ray tomography stage. This shielded container allows single particles to be removed from the hot cell and transported to the tomography instrument for imaging. The shielding also reduces gamma radiation interference in the detector and electronics. Image sets using 3200 particle orientations were acquired to support high-resolution three-dimensional tomographic reconstruction.

Mechanical polishing to reveal particle cross sections was achieved by mounting particles in epoxy and grinding/polishing with diamond suspensions using various methods. Vacuum back-potting was used to prevent damage to the internal structure and improve the quality of the final polished cross section. Kernels and coating layers were imaged using an optical microscope. Scanning electron microscopy (SEM) was performed on some samples to provide additional information. Back-scattered electron imaging was used to reveal the $\mathrm{SiC}$ grain structure and detect heavy metal clusters outside of the kernel. Wavelength Dispersive Spectrometry (WDS) coupled with Energy Dispersive Spectrometry (EDS) was used to identify fission product clusters.

\section{Results of PIE on Three As-Irradiated AGR-1 Compacts}

The AGR-1 irradiation test train consisted of six independently monitored capsules, each containing twelve compacts. Four different fuel lots were irradiated, a baseline coated particle designed to replicate high-performance German TRISO coatings, and three variants with slightly different $\mathrm{SiC}$ or IPyC microstructure. Compact 6-1-1 came from the Baseline fuel lot, Compact 4-4-2 came from the Variant 3 fuel lot (alternate $\mathrm{SiC}$ deposition process), and Compact 5-2-3 came from the Variant 1 fuel lot (lower density IPyC). Compact 5-2-3 was specifically selected for PIE because ${ }^{134} \mathrm{Cs}$ was detected in the Capsule 3 internals, with the highest concentration on the graphite holder at the location of this compact. Given that no fission product gas was released during the AGR-1 irradiation test, it was hypothesized that a particle with defective $\mathrm{SiC}$, but intact pyrocarbon, was contained in Compact 5-2-3.

\section{$D L B L$ results}

Table 1 summarizes the results of the DLBL analyses for some of the key fission products. These results indicate how much of each fission product could be detected outside of intact $\mathrm{SiC}$ before and after the burn step, which oxidizes exposed carbon and any exposed fission products not previously leached. Results are presented in terms of the fractional release and the equivalent number of exposed kernels. The release fraction was determined by dividing the measured amount of each isotope by the value calculated to have been generated in the fuel by the three-year irradiation (after first compensating for radioactive decay between the end of the irradiation and the time of analysis). The equivalent number of exposed kernels was determined from the release fraction based on the average number of particles in each compact. 
Table 1. Summary of DLBL results on three as-irradiated AGR-1 compacts

\begin{tabular}{|c|c|c|c|c|c|c|c|c|c|}
\hline \multirow{2}{*}{$\begin{array}{l}\text { Fission } \\
\text { Product }\end{array}$} & \multicolumn{3}{|c|}{ Compact 6-1-1 } & \multicolumn{3}{|c|}{ Compact 4-4-2 } & \multicolumn{3}{|c|}{ Compact 5-2-3 } \\
\hline & pre-burn & post burn & total & pre-burn & post burn & total & pre-burn & post burn & total \\
\hline${ }^{90} \mathrm{Sr}$ & $\begin{array}{c}4.5 \mathrm{E}-4 \\
(1.9)\end{array}$ & $\begin{array}{l}1.5 \mathrm{E}-4 \\
(0.61)\end{array}$ & $\begin{array}{c}6.0 \mathrm{E}-4 \\
(2.5)\end{array}$ & $\begin{array}{l}1.2 \mathrm{E}-5 \\
(0.05)\end{array}$ & $\begin{array}{l}4.7 \mathrm{E}-6 \\
(0.02)\end{array}$ & $\begin{array}{l}1.7 \mathrm{E}-5 \\
(0.07)\end{array}$ & $\begin{array}{c}1.8 \mathrm{E}-3 \\
(7.7)\end{array}$ & $\begin{array}{c}1.3 \mathrm{E}-3 \\
(5.4)\end{array}$ & $\begin{array}{c}3.1 \mathrm{E}-3 \\
(13)\end{array}$ \\
\hline${ }^{105} \mathrm{Pd}$ & $\begin{array}{c}6.0 \mathrm{E}-3 \\
(25)\end{array}$ & $\begin{array}{l}5.4 \mathrm{E}-3 \\
(22)\end{array}$ & $\begin{array}{c}1.1 \mathrm{E}-2 \\
(47)\end{array}$ & $\begin{array}{c}2.3 \mathrm{E}-3 \\
(10)\end{array}$ & $\begin{array}{c}9.0 \mathrm{E}-3 \\
(37)\end{array}$ & $\begin{array}{c}1.1 \mathrm{E}-2 \\
(47)\end{array}$ & $\begin{array}{l}1.2 \mathrm{E}-4 \\
(0.48)\end{array}$ & $\begin{array}{c}2.1 \mathrm{E}-2 \\
(86)\end{array}$ & $\begin{array}{c}2.1 \mathrm{E}-2 \\
(86)\end{array}$ \\
\hline${ }^{110 \mathrm{~m}} \mathrm{Ag}$ & $\begin{array}{c}7.9 \mathrm{E}-2 \\
(328)\end{array}$ & $\begin{array}{c}3.8 \mathrm{E}-2 \\
(158)\end{array}$ & $\begin{array}{l}1.2 \mathrm{E}-1 \\
(486)\end{array}$ & $\begin{array}{c}2.0 \mathrm{E}-2 \\
(82)\end{array}$ & $\begin{array}{c}2.9 \mathrm{E}-3 \\
(12)\end{array}$ & $\begin{array}{c}2.3 \mathrm{E}-2 \\
(94)\end{array}$ & $\begin{array}{c}3.3 \mathrm{E}-3 \\
(14)\end{array}$ & n.d. & $\begin{array}{c}3.3 \mathrm{E}-3 \\
(14)\end{array}$ \\
\hline${ }^{134} \mathrm{Cs}$ & $\begin{array}{l}3.9 \mathrm{E}-6 \\
(0.02)\end{array}$ & $\begin{array}{l}1.5 \mathrm{E}-5 \\
(0.06)\end{array}$ & $\begin{array}{l}1.9 \mathrm{E}-5 \\
(0.08)\end{array}$ & $\begin{array}{l}1.1 \mathrm{E}-5 \\
(0.05)\end{array}$ & $\begin{array}{l}8.1 \mathrm{E}-7 \\
(0.003)\end{array}$ & $\begin{array}{l}1.2 \mathrm{E}-5 \\
(0.05)\end{array}$ & $\begin{array}{c}4.0 \mathrm{E}-5 \\
(0.17)\end{array}$ & $\begin{array}{l}7.8 \mathrm{E}-6 \\
(0.03)\end{array}$ & $\begin{array}{c}4.8 \mathrm{E}-5 \\
(0.20)\end{array}$ \\
\hline${ }^{137} \mathrm{Cs}$ & $\begin{array}{l}7.3 \mathrm{E}-6 \\
(0.03)\end{array}$ & $\begin{array}{l}7.3 \mathrm{E}-5 \\
(0.30)\end{array}$ & $\begin{array}{l}8.0 \mathrm{E}-5 \\
(0.33)\end{array}$ & $\begin{array}{l}2.3 \mathrm{E}-5 \\
(0.09)\end{array}$ & $\begin{array}{l}7.5 \mathrm{E}-6 \\
(0.03)\end{array}$ & $\begin{array}{l}3.0 \mathrm{E}-5 \\
(0.12)\end{array}$ & $\begin{array}{l}5.2 \mathrm{E}-5 \\
(0.22)\end{array}$ & $\begin{array}{l}1.5 \mathrm{E}-5 \\
(0.06)\end{array}$ & $\begin{array}{c}6.7 \mathrm{E}-5 \\
(0.28)\end{array}$ \\
\hline${ }^{144} \mathrm{Ce}$ & $\begin{array}{l}2.3 \mathrm{E}-5 \\
(0.09)\end{array}$ & $\begin{array}{c}6.7 \mathrm{E}-4 \\
(2.8)\end{array}$ & $\begin{array}{c}6.9 \mathrm{E}-4 \\
(2.9)\end{array}$ & $\begin{array}{l}1.3 \mathrm{E}-5 \\
(0.05)\end{array}$ & $\begin{array}{l}4.3 \mathrm{E}-7 \\
(0.002)\end{array}$ & $\begin{array}{l}1.3 \mathrm{E}-5 \\
(0.05)\end{array}$ & $\begin{array}{l}1.7 \mathrm{E}-4 \\
(0.71)\end{array}$ & $\begin{array}{c}1.4 \mathrm{E}-3 \\
(5.6)\end{array}$ & $\begin{array}{c}1.6 \mathrm{E}-3 \\
(6.3)\end{array}$ \\
\hline${ }^{152} \mathrm{Sm}$ & $\begin{array}{c}3.1 \mathrm{E}-4 \\
(1.3)\end{array}$ & $\begin{array}{c}6.3 \mathrm{E}-4 \\
(2.6)\end{array}$ & $\begin{array}{c}9.4 \mathrm{E}-4 \\
(3.9)\end{array}$ & $\begin{array}{l}3.4 \mathrm{E}-5 \\
(0.14)\end{array}$ & $\begin{array}{l}6.0 \mathrm{E}-5 \\
(0.25)\end{array}$ & $\begin{array}{l}9.4 \mathrm{E}-5 \\
(0.39)\end{array}$ & $\begin{array}{l}9.4 \mathrm{E}-6 \\
(0.04)\end{array}$ & $\begin{array}{c}4.7 \mathrm{E}-3 \\
(20)\end{array}$ & $\begin{array}{c}4.7 \mathrm{E}-3 \\
(20)\end{array}$ \\
\hline${ }^{154} \mathrm{Eu}$ & $\begin{array}{c}2.5 \mathrm{E}-3 \\
(10)\end{array}$ & $\begin{array}{c}1.1 \mathrm{E}-2 \\
(44)\end{array}$ & $\begin{array}{c}1.4 \mathrm{E}-2 \\
(54)\end{array}$ & $\begin{array}{c}2.7 \mathrm{E}-4 \\
(1.1)\end{array}$ & $\begin{array}{c}3.4 \mathrm{E}-4 \\
(1.4)\end{array}$ & $\begin{array}{c}6.1 \mathrm{E}-4 \\
(2.5)\end{array}$ & $\begin{array}{c}2.2 \mathrm{E}-3 \\
(9.1)\end{array}$ & $\begin{array}{c}4.1 \mathrm{E}-3 \\
(17)\end{array}$ & $\begin{array}{c}6.3 \mathrm{E}-3 \\
(26)\end{array}$ \\
\hline${ }^{155} \mathrm{Eu}$ & $\begin{array}{c}2.6 \mathrm{E}-3 \\
(11)\end{array}$ & $\begin{array}{c}1.2 \mathrm{E}-2 \\
(49)\end{array}$ & $\begin{array}{c}1.5 \mathrm{E}-2 \\
(60)\end{array}$ & $\begin{array}{c}2.9 \mathrm{E}-4 \\
(1.2)\end{array}$ & $\begin{array}{c}4.1 \mathrm{E}-4 \\
(1.7)\end{array}$ & $\begin{array}{l}\text { 7.0E-4 } \\
(2.9)\end{array}$ & $\begin{array}{c}2.5 \mathrm{E}-3 \\
(11)\end{array}$ & $\begin{array}{c}4.7 \mathrm{E}-3 \\
(19)\end{array}$ & $\begin{array}{c}7.2 \mathrm{E}-3 \\
(30)\end{array}$ \\
\hline${ }^{235} \mathrm{U}$ & $\begin{array}{l}1.5 \mathrm{E}-5 \\
(0.06)\end{array}$ & $\begin{array}{l}3.6 \mathrm{E}-5 \\
(0.15)\end{array}$ & $\begin{array}{l}5.1 \mathrm{E}-5 \\
(0.21)\end{array}$ & $\begin{array}{l}2.3 \mathrm{E}-5 \\
(0.09)\end{array}$ & $\begin{array}{l}1.8 \mathrm{E}-5 \\
(0.07)\end{array}$ & $\begin{array}{l}4.1 \mathrm{E}-5 \\
(0.16)\end{array}$ & $\begin{array}{l}5.6 \mathrm{E}-6 \\
(0.02)\end{array}$ & $\begin{array}{l}5.3 \mathrm{E}-5 \\
(0.22)\end{array}$ & $\begin{array}{c}5.9 \mathrm{E}-5 \\
(0.24)\end{array}$ \\
\hline${ }^{239} \mathrm{Pu}$ & $\begin{array}{c}3.8 \mathrm{E}-5 \\
(0.16)\end{array}$ & $\begin{array}{c}2.5 \mathrm{E}-4 \\
(1.0)\end{array}$ & $\begin{array}{c}2.9 \mathrm{E}-4 \\
(1.2)\end{array}$ & $\begin{array}{l}1.4 \mathrm{E}-5 \\
(0.06)\end{array}$ & $\begin{array}{l}2.4 \mathrm{E}-5 \\
(0.10)\end{array}$ & $\begin{array}{l}3.8 \mathrm{E}-6 \\
(0.16)\end{array}$ & $\begin{array}{l}2.8 \mathrm{E}-5 \\
(0.12)\end{array}$ & $\begin{array}{c}3.9 \mathrm{E}-4 \\
(1.6)\end{array}$ & $\begin{array}{c}4.2 \mathrm{E}-4 \\
(1.7)\end{array}$ \\
\hline
\end{tabular}

Release values are reported as the fraction of compact inventory and the equivalent number of exposed kernels (in parentheses). "n.d." indicates a value was not determined because the measure values were below the detection threshold.

Detection of uranium during DLBL is a good indicator for exposed kernels. If none of the three outer TRISO layers (inner pyrocarbon, $\mathrm{SiC}$, and outer pyrocarbon) are intact, then acid will attack the kernel during the pre-burn leaching steps. If good pyrocarbon protects a $\mathrm{SiC}$ that is not intact, then the burn step will remove the pyrocarbon and expose the kernel to post-burn leaching. Greater than $90 \%$ of the uranium in an exposed kernel is typically leached by the hot acid. The amount of uranium in all three compacts was well below what would be expected for an exposed kernel, so neither of these defects appears to be present in the particles analyzed. Note, however, that all the particles were not subjected to the burn-leach process, and that those particles most likely to have defective SiC were intentionally removed by IMGA based on their low ${ }^{137} \mathrm{Cs}$ content. This was to allow for further analysis of the defective particle microstructure without the disruption that would occur from burn-leach.

Silver, palladium, and europium showed the highest fractional release of fission products that passed through the $\mathrm{SiC}$ and were still retained in the compact to be detected by DLBL. Silver was also released in significant quantity from each compact during irradiation. The silver in Compact 5-2-3 was unusually low compared to the other two compacts in Table 1, possibly due to greater release from the compact during irradiation. Irradiation capsule components have been analyzed for ${ }^{110 \mathrm{~m}} \mathrm{Ag}$ and gamma scanning has been completed on many of the compacts prior to deconsolidation. The varied silver release from each compact will be considered further in the final AGR-1 PIE summary report. 
It is interesting to consider the overall behavior of strontium, cerium, samarium, europium, and plutonium, which may be mobile in the fuel particle as carbides. The DLBL results for Compact 4-4-2 showed lower amounts of all these elements. The possibility that this may be related to the Variant $3 \mathrm{SiC}$ microstructure should be investigated. Variant $3 \mathrm{SiC}$ had smaller grain size and a higher concentration of small, localized defects that could trap elements diffusing through the layer.

\section{IMGA results}

In between DL and BL, all the particles recovered from each compact were surveyed using the IMGA to sort out any with unusual inventories of ${ }^{144} \mathrm{Ce},{ }^{137} \mathrm{Cs}$, or ${ }^{110 \mathrm{~m}} \mathrm{Ag}$. These $80-100$ second gamma scans also provided a determination of the cesium retention by the particles. Figure 2 shows the ${ }^{137} \mathrm{Cs}$ distribution measured for Compact 6-1-1, and this result is representative of the results for the other compacts. The narrow spread in the ${ }^{137} \mathrm{Cs}$ content is at least partially due to analysis uncertainty, and the average retention value of $99 \%$ supports the conclusions that cesium was well retained and that the calculated inventory was accurately predicted.

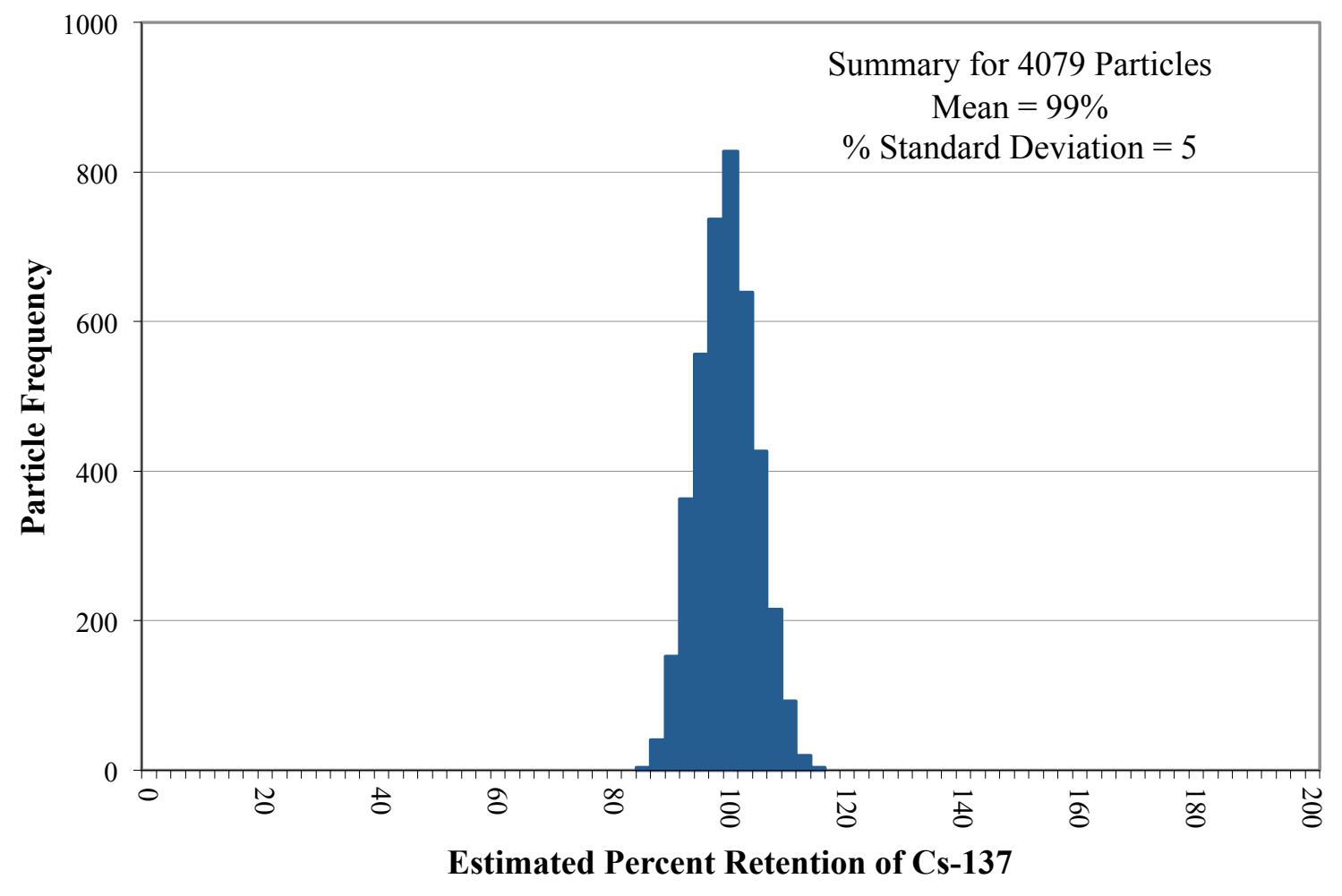

Figure 2. Estimated fraction of ${ }^{137} \mathrm{Cs}$ retained in particles from Compact 6-1-1 based on calculated inventory and adjusted for variation in fissionable material and burn-up using the measured ${ }^{144} \mathrm{Ce}$ activity. Results suggest low Cs release and good accuracy in the calculated inventory.

Two particles were detected during the IMGA survey of the particles recovered from Compact 5-2-3 that each had relative cesium content approximately $30 \%$ below the mean. These were set aside for further analysis to determine if they were responsible for the ${ }^{134} \mathrm{Cs}$ release detected in the irradiation capsule. The total missing cesium from these two particles was in good agreement with gamma analysis of the Capsule 5 components, which detected an elevated ${ }^{134} \mathrm{Cs}$ level equivalent to $\sim 60 \%$ of one particle's inventory.

Silver and europium were two of the fission products most readily released during irradiation, so emphasis was given to analyzing their retention by the individual fuel particles. Accurate detection of the gamma-emitting isotopes of silver and europium required 4-6 hour acquisition of the gamma spectrum 
from each particle. Therefore, IMGA distributions for these isotopes were only determined using a randomly selected representative subset of 57-122 particles from each compact. The gamma scanning for 4-6 hours also provided data on several other gamma-emitting isotopes (i.e., ${ }^{95} \mathrm{Zr},{ }^{106} \mathrm{Ru},{ }^{125} \mathrm{Sb},{ }^{134} \mathrm{Cs}$, ${ }^{137} \mathrm{Cs}$, and $\left.{ }^{144} \mathrm{Ce}\right)$.

Europium behavior was similar for all compacts. Figure 3 shows a representative ${ }^{154}$ Eu distribution obtained for Compact 4-4-2. Similar to Figure 2, the europium retention has been plotted as a ratio of the measured value versus the calculated inventory at the end of irradiation. Like cesium, the europium distribution was narrow; this is indicative of uniform europium retention behavior for all the particles. However, the calculated average retention does not agree with the europium release determined from DLBL and analysis of the irradiation capsule components. These analyses indicated europium release of less than a few percent. For most of the compacts, the measured versus calculated europium inventory determined by IMGA has averaged between $0.84-0.86$. This indicates that the calculated inventory for europium is higher than the actual amount of europium generated in the fuel by the three-year irradiation.

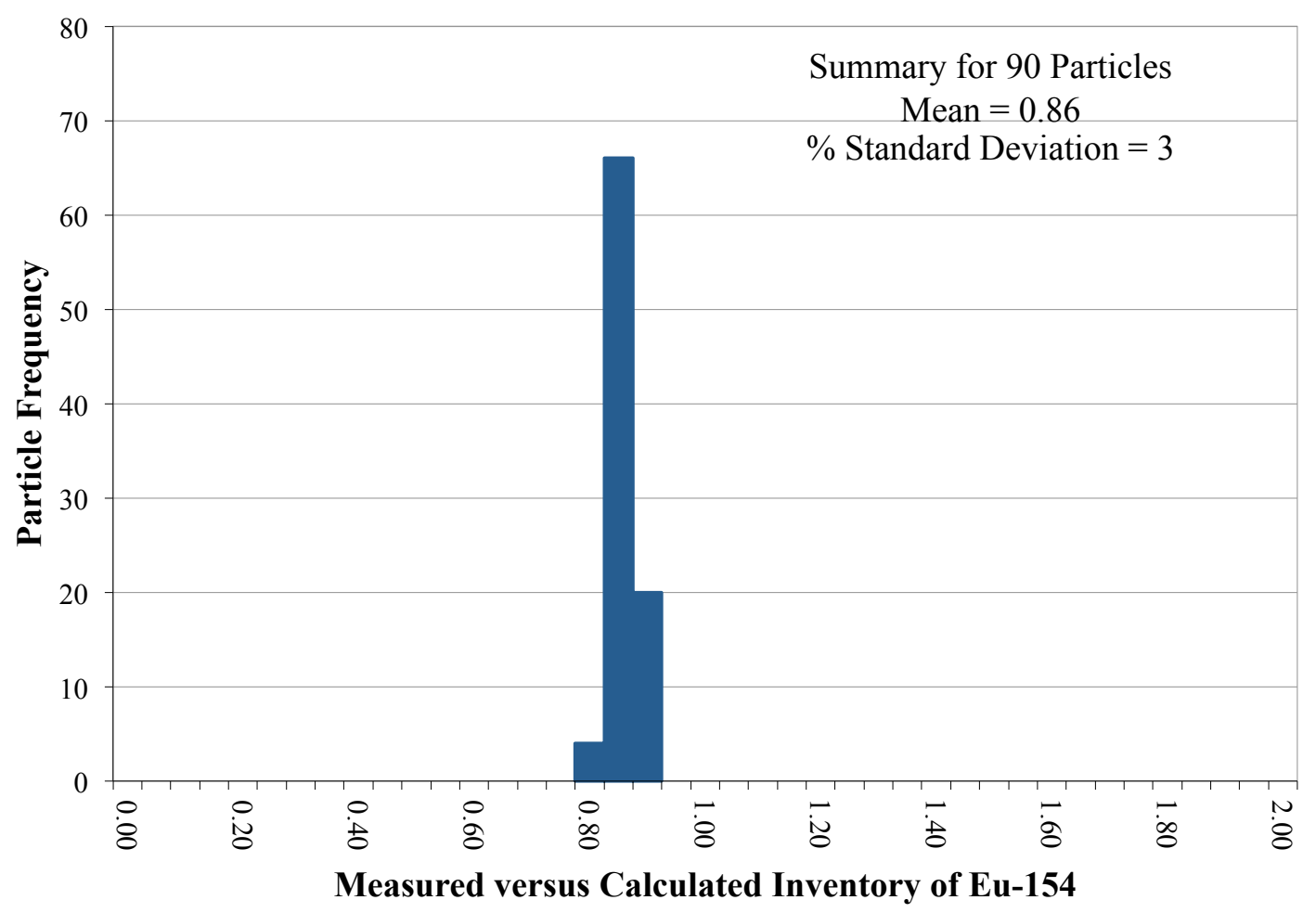

Figure 3. Ratio of ${ }^{154} \mathrm{Eu}$ retained in 90 particles from Compact 4-4-2 versus calculated inventory, adjusted for variation in fissionable material and burn-up using the measured ${ }^{137} \mathrm{Cs}$ activity.

The IMGA data from the 4-6 hour scans showed that the silver retention within each compact varied considerably from particle-to-particle. Figure 4 shows the broad distribution in ${ }^{110 \mathrm{~m}} \mathrm{Ag}$ measured for the random particle sample from Compact 4-4-2. There is a broad peak centered around an average retention close to the full calculated inventory of ${ }^{110 \mathrm{~m}} \mathrm{Ag}$, with a low-end tail indicating a sub-population of particles with lower silver retention. This general trend was also seen for Compacts 6-1-1 and 5-2-3, but the subpopulations with lower retention were larger and shifted down, with some particles having an undetectable activity from ${ }^{110 \mathrm{~m}} \mathrm{Ag}$ (Figure 5 and Figure 6). Particles with low silver retention were analyzed by $\mathrm{x}$-ray tomography and materialography for comparison to particles with average silver retention. 


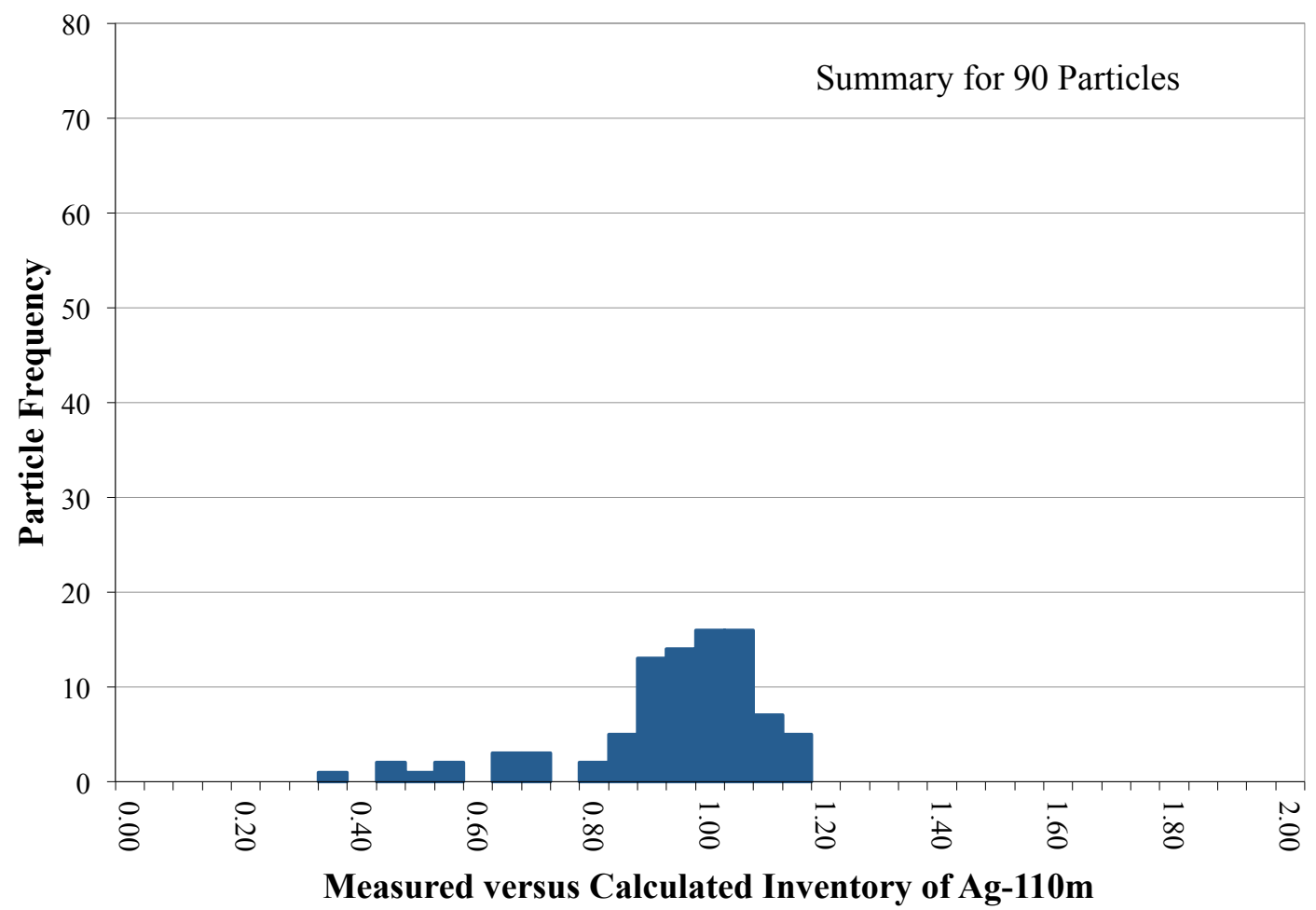

Figure 4. Ratio of ${ }^{110 \mathrm{~m}} \mathrm{Ag}$ retained in 90 particles from Compact 4-4-2 versus calculated inventory, adjusted for variation in fissionable material and burn-up using the measured ${ }^{137} \mathrm{Cs}$ activity.

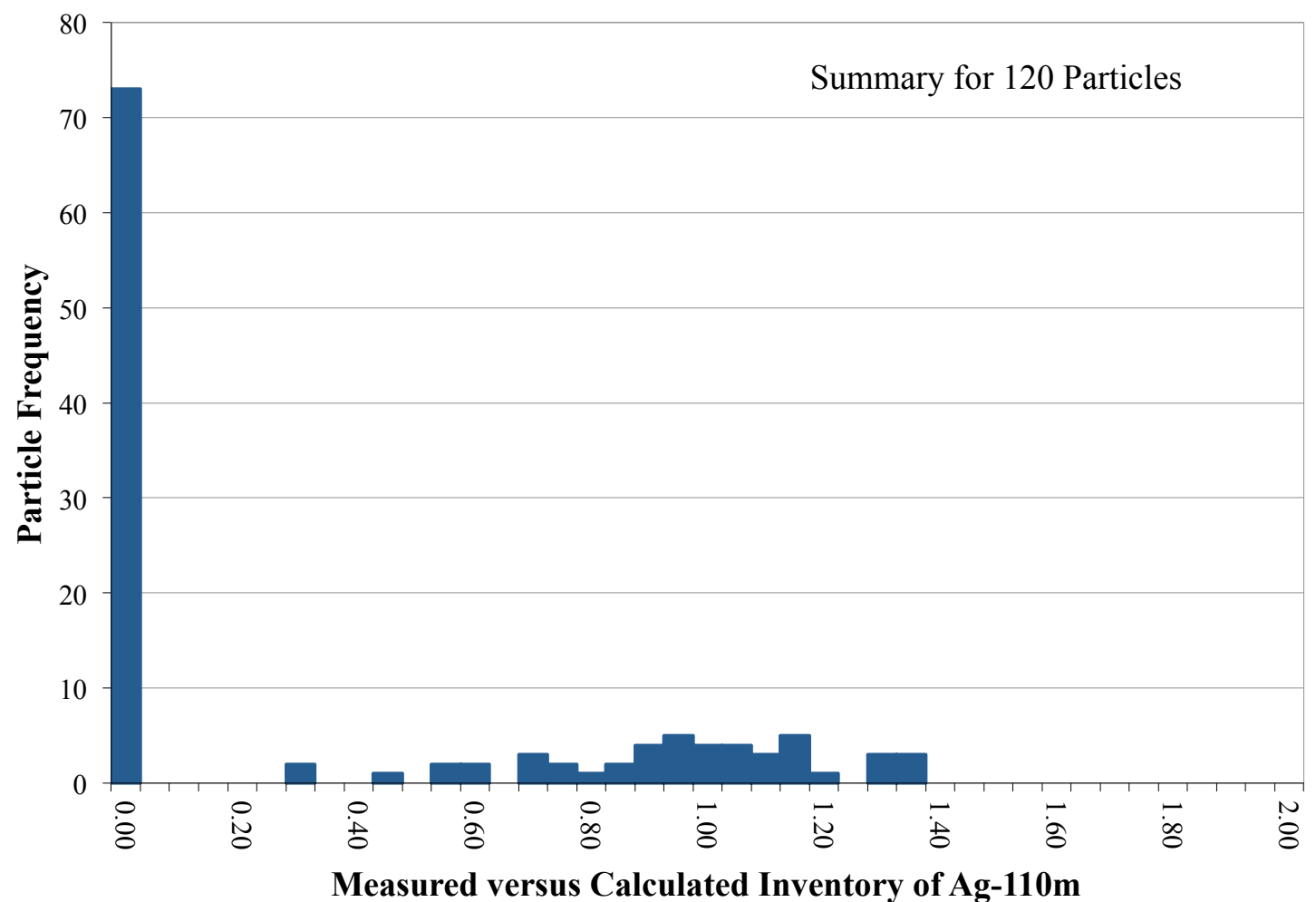

Figure 5. Ratio of ${ }^{110 \mathrm{~m}} \mathrm{Ag}$ retained in 120 particles from Compact 6-1-1 versus calculated inventory, adjusted for variation in fissionable material and burn-up using the measured ${ }^{137} \mathrm{Cs}$ activity. 


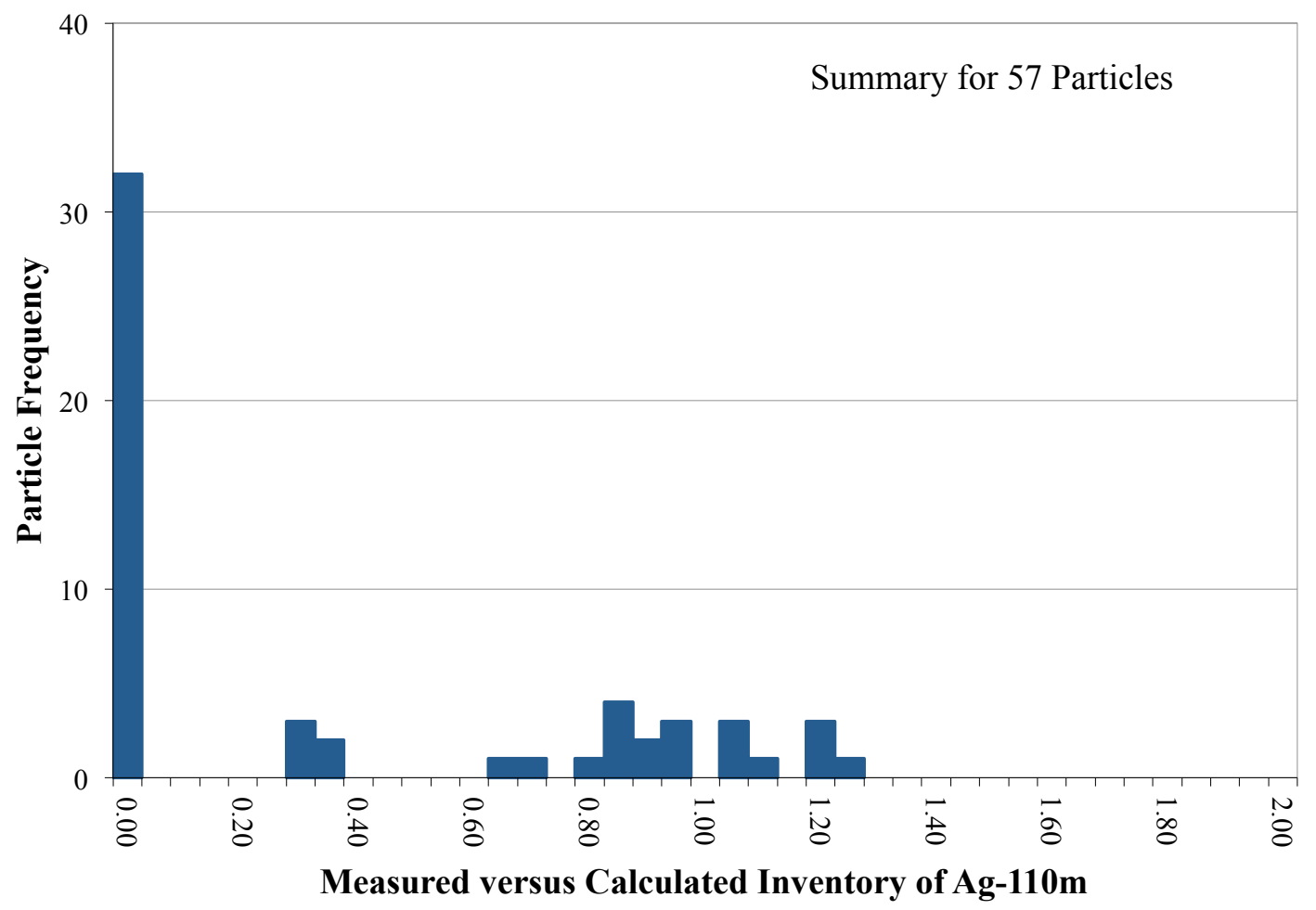

Figure 6. Ratio of ${ }^{110 \mathrm{~m}} \mathrm{Ag}$ retained in 57 particles from Compact 5-2-3 versus calculated inventory, adjusted for variation in fissionable material and burn-up using the measured ${ }^{137} \mathrm{Cs}$ activity.

X-ray tomography results

X-ray tomography was performed on particles selected from each of the three as-irradiated compacts. Figure 7 shows one typical irradiated particle microstructure with no apparent coating damage beyond the separation of the buffer from the IPyC due to the irradiation-induced densification of the buffer. In some cases, the buffer densification causes the layer to fracture, and the kernel will often expand into the opening between the buffer fragments. This behavior was reported in detail in INL/EXT-12-25301, Ceramographic Examinations of Irradiated AGR-1 Fuel Compacts, and Figure 8 shows a typical example. Also visible in Figure 8 is a fission product cluster at the IPyC/SiC interface. Particles were selected for x-ray tomography based on their ${ }^{110 \mathrm{~m}} \mathrm{Ag}$ retention. Particles in the sub-populations with undetectable silver (Figure 5 and Figure 6) were compared to those with average and above average silver content. No correlation between silver retention and coating microstructure has yet been discovered.

Figure 9 and Figure 10 show one of the two particles from Compact 5-2-3 with lower than average cesium retention. It can be seen that the buffer layer fractured during irradiation. The buffer fracture and delamination appears to have led to fracture of the IPyC and ultimate cracking of the SiC layer. Figure 11 and Figure 12 show the second particle from Compact 5-2-3 with lower than average cesium retention. This particle shows similar cracking of the buffer, IPyC, and SiC. Note that in both particles, the IPyC crack occurred where the buffer was still attached to the IPyC. It is expected that the outer pyrocarbon $(\mathrm{OPyC})$ layer of these particles remained intact, based on the lack of ${ }^{85} \mathrm{Kr}$ release during irradiation or kernel leaching during electrolytic deconsolidation. The entire OPyC layer was not visible in the $\mathrm{x}$-ray images of the first particle, because of imaging conditions. The second particle was imaged with lower energy x-rays and thicker epoxy overcoat; no OPyC cracks could be resolved. Both particles also show bright spots in the $\mathrm{x}$-ray images that indicate fission products clustered at the site of the defect. These are more prevalent in the second particle, and there may be some corrosion in the $\mathrm{SiC}$ at the defect site. 


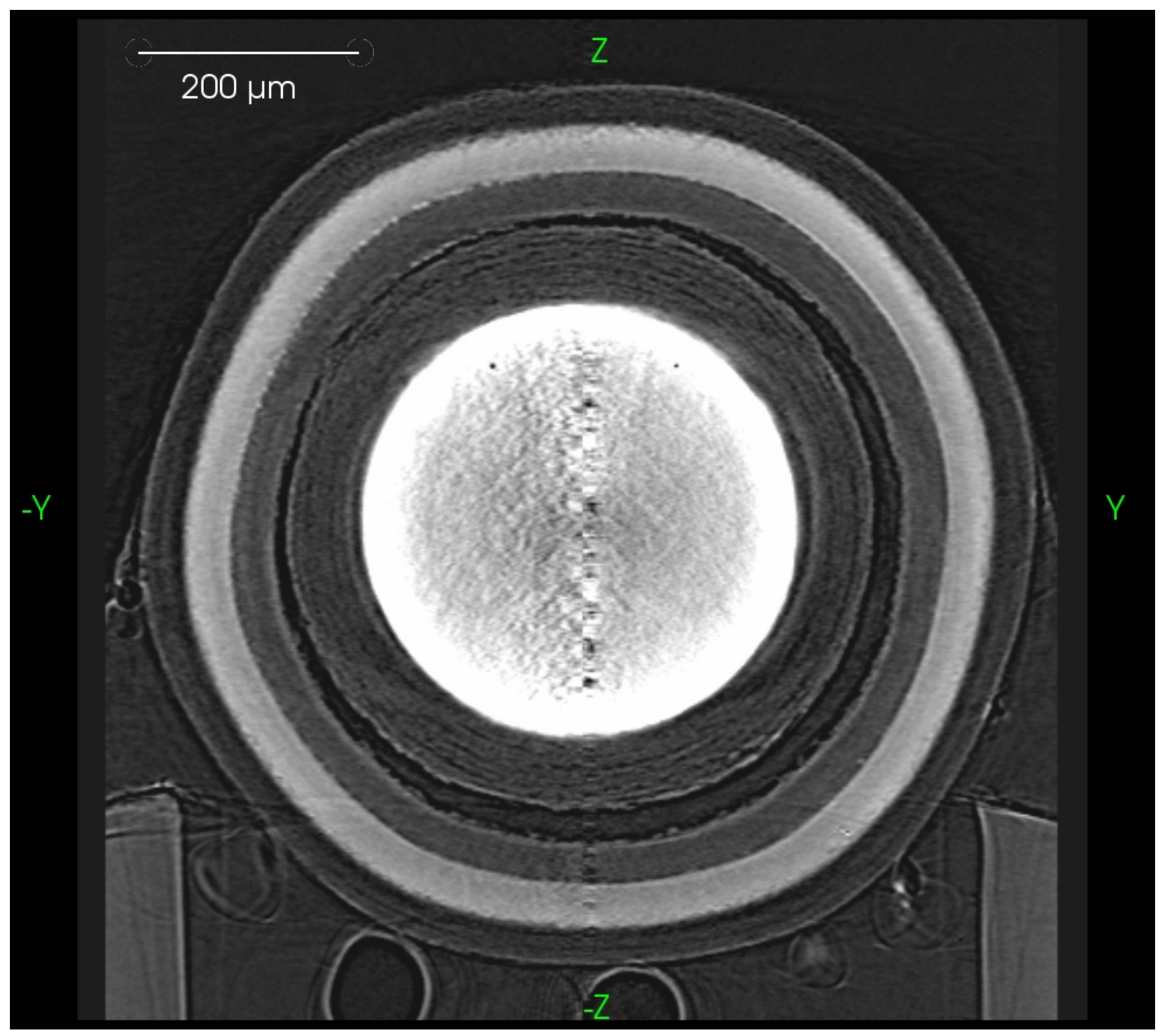

Figure 7. X-ray tomograph of a typical irradiated particle microstructure showing a densified buffer and no apparent coating damage (particle from Compact 4-4-2).

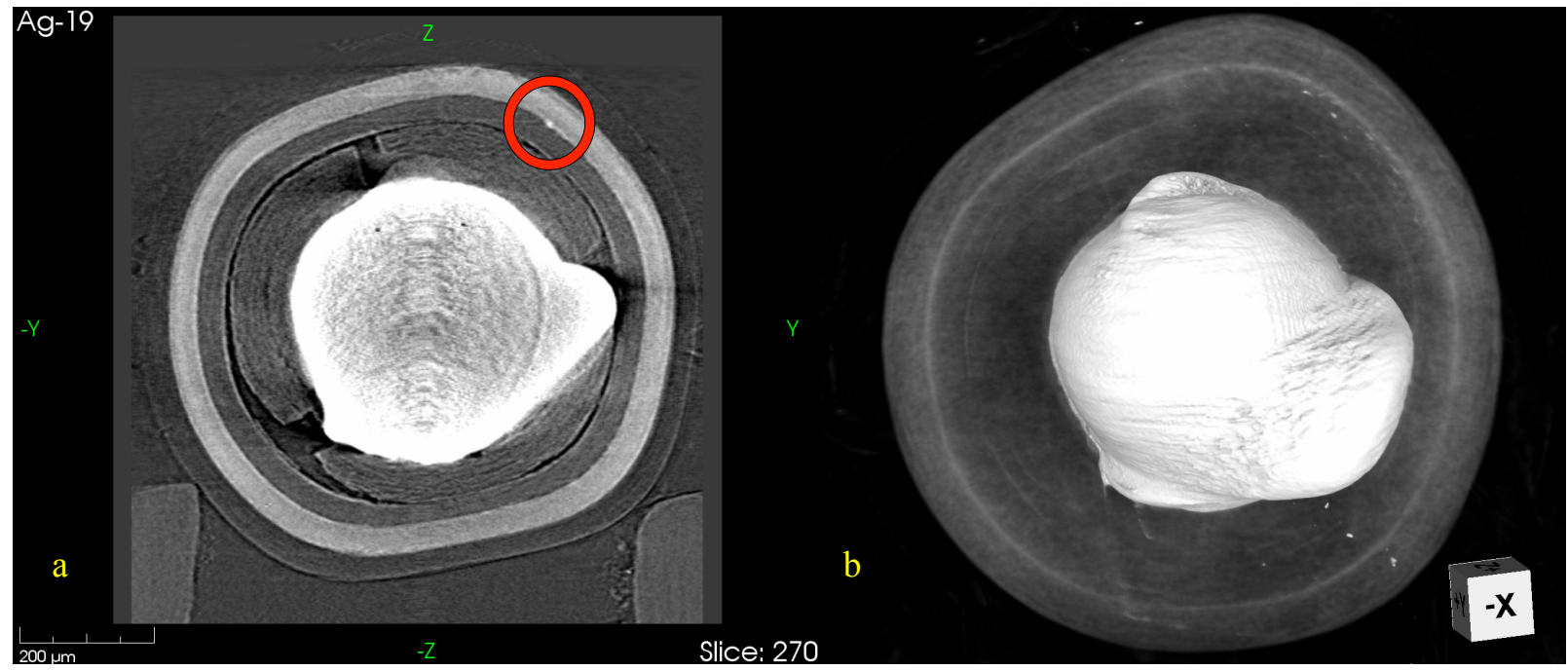

Figure 8. X-ray tomograph (a) and 3-D rendering (b) of a particle with fractured buffer and protruding kernel (particle from Compact 6-1-1). Also visible (circled) is a fission product cluster at the IPyC/SiC interface. 


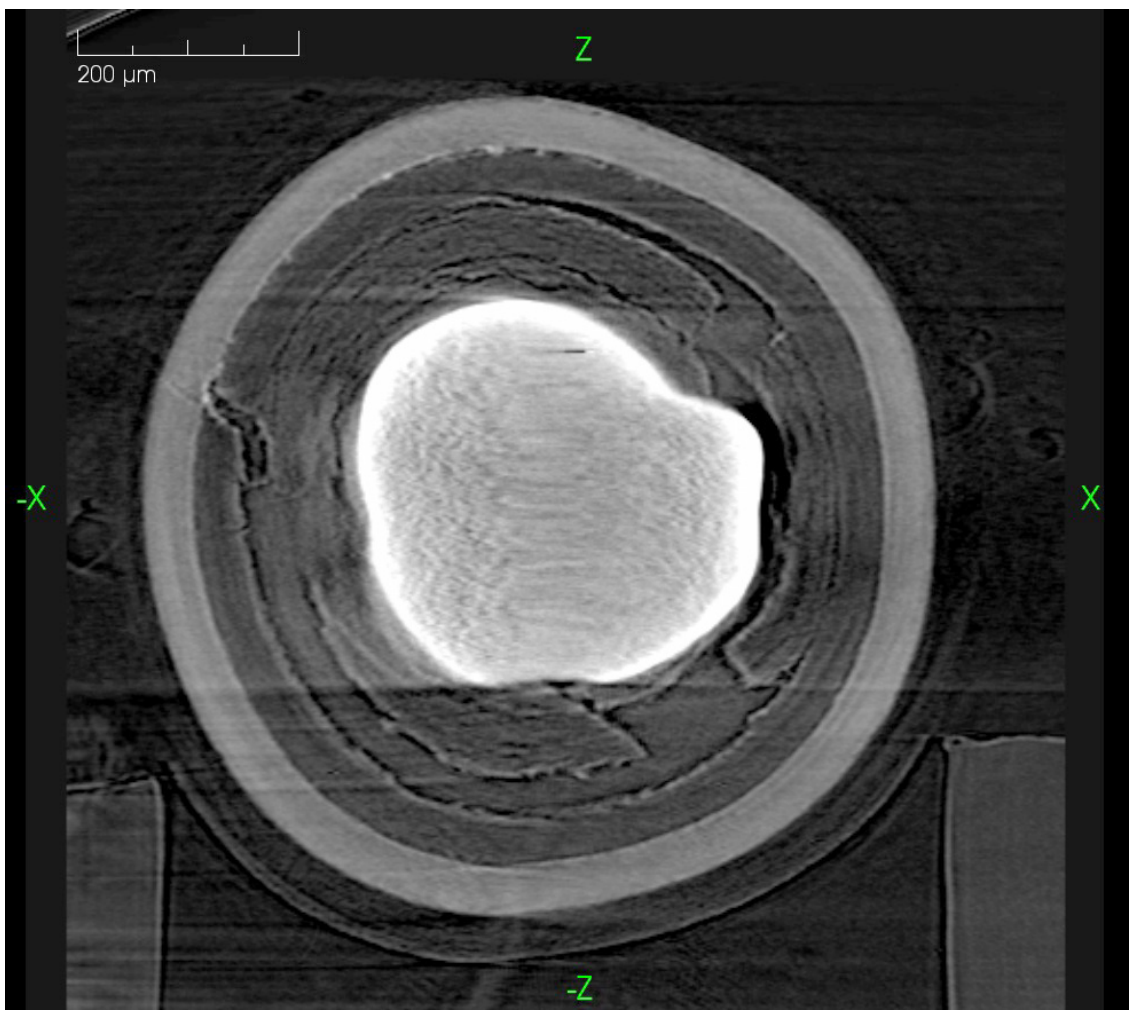

Figure 9. X-ray tomograph of first particle with reduced cesium retention from Compact 5-2-3. Buffer fracture and delamination has apparently led to failure of the IPyC and SiC layers.

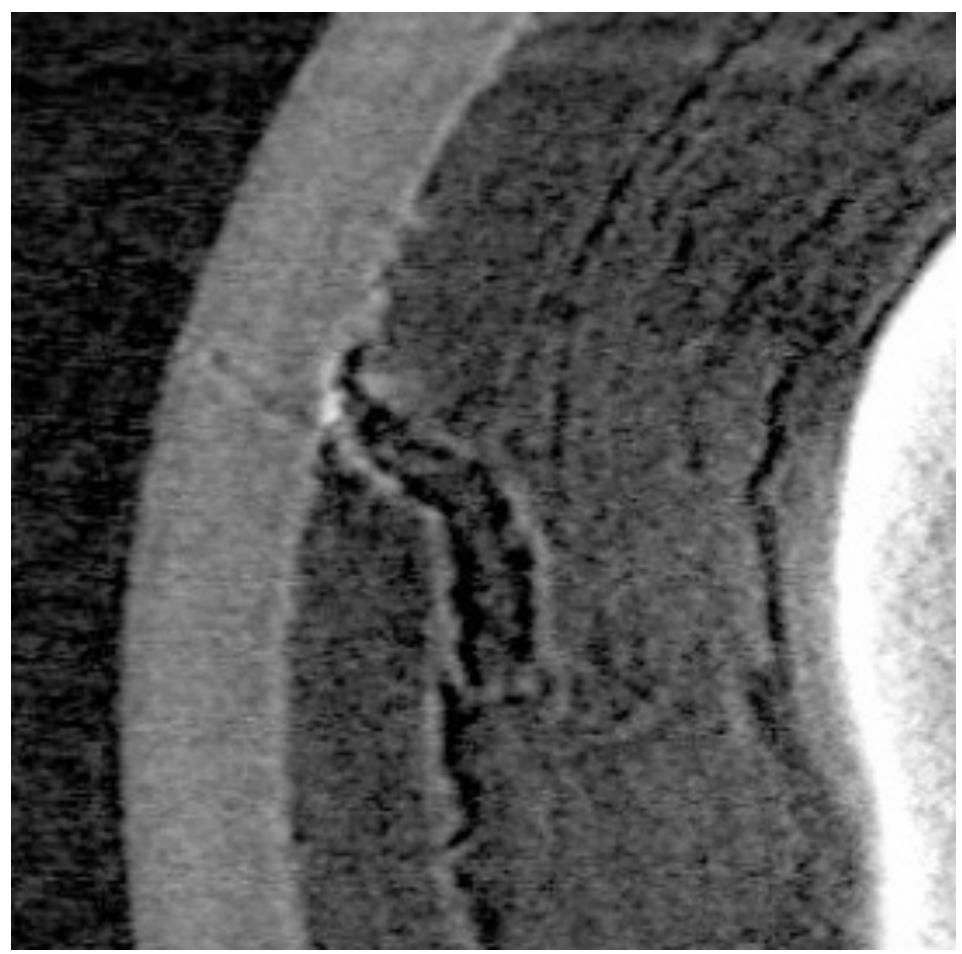

Figure 10. Close-up of particle in Figure 9 using higher resolution tomographic reconstruction. A fine crack through the $\mathrm{SiC}$ is evident. 


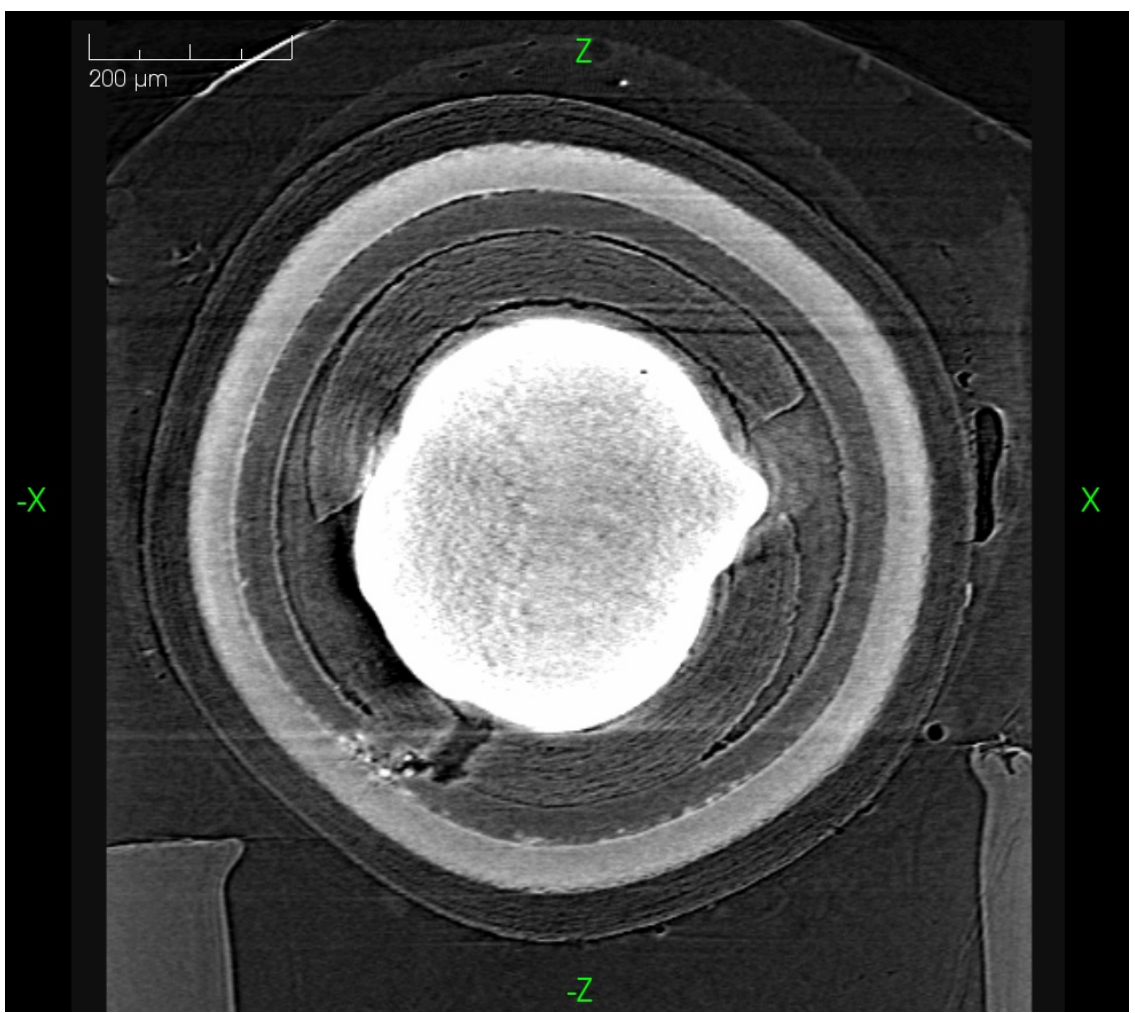

Figure 11. X-ray tomograph of second particle with reduced cesium retention from Compact 5-2-3. Buffer fracture and delamination has apparently led to failure of the IPyC and SiC layers. Bright spots at location of IPyC/SiC failure are fission product clusters.

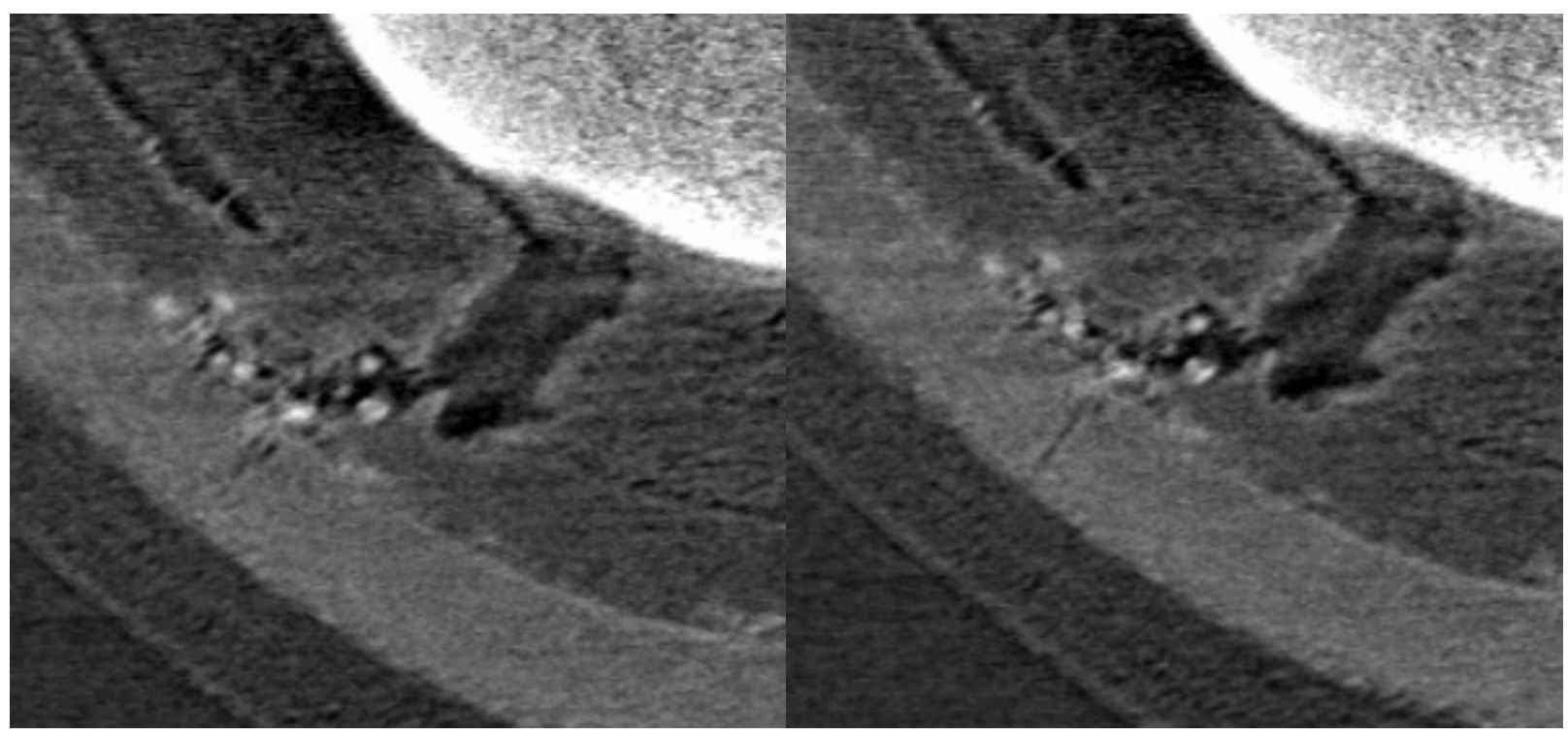

Figure 12. Two close-up images of particle in Figure 11 using higher resolution tomographic reconstruction. A fine crack through the $\mathrm{SiC}$ is evident and there may be some fission product corrosion near the IPyC/SiC interface. 


\section{Materialography results}

Although x-ray tomography provides definite advantages in terms of non-destructive three-dimensional analysis, mechanical cross sectioning allows for higher resolution imaging, elemental analysis, and investigation of kernel microstructure. Figure 13 and Figure 14 show images obtained using an optical microscope of a polished cross section of a particle from Compact 6-1-1. The porous nature of the irradiated kernel, not visible using low energy x-rays, can be clearly seen in the polished cross section. Some residual buffer is evident on the inside surface of the IPyC layer providing insight on how this interface delaminated. The interface between the IPyC and the $\mathrm{SiC}$ remained intimately stitched, but there is a slight gap between the $\mathrm{SiC}$ and the $\mathrm{OPyC}$ that needs further investigation. Figure 15 shows a particle from Compact 5-2-3 with a fractured buffer and protruding kernel. The absence of an intact buffer to restrain kernel swelling resulted in much larger gas pockets in the kernel interior.

SEM was performed on some polished particle cross sections to investigate fission product clustering outside of the kernel. Figure 16 shows a back-scattered electron image, where fission product clusters in the TRISO layers appear as bright spots. WDS analysis (Figure 17) identified many of these fission product clusters to contain palladium and uranium. Further studies are needed to consider the possible connection between these fission product clusters and silver transport through intact SiC. Additional observations on Compact 6-4-3, discussed in the next section, support this possibility.

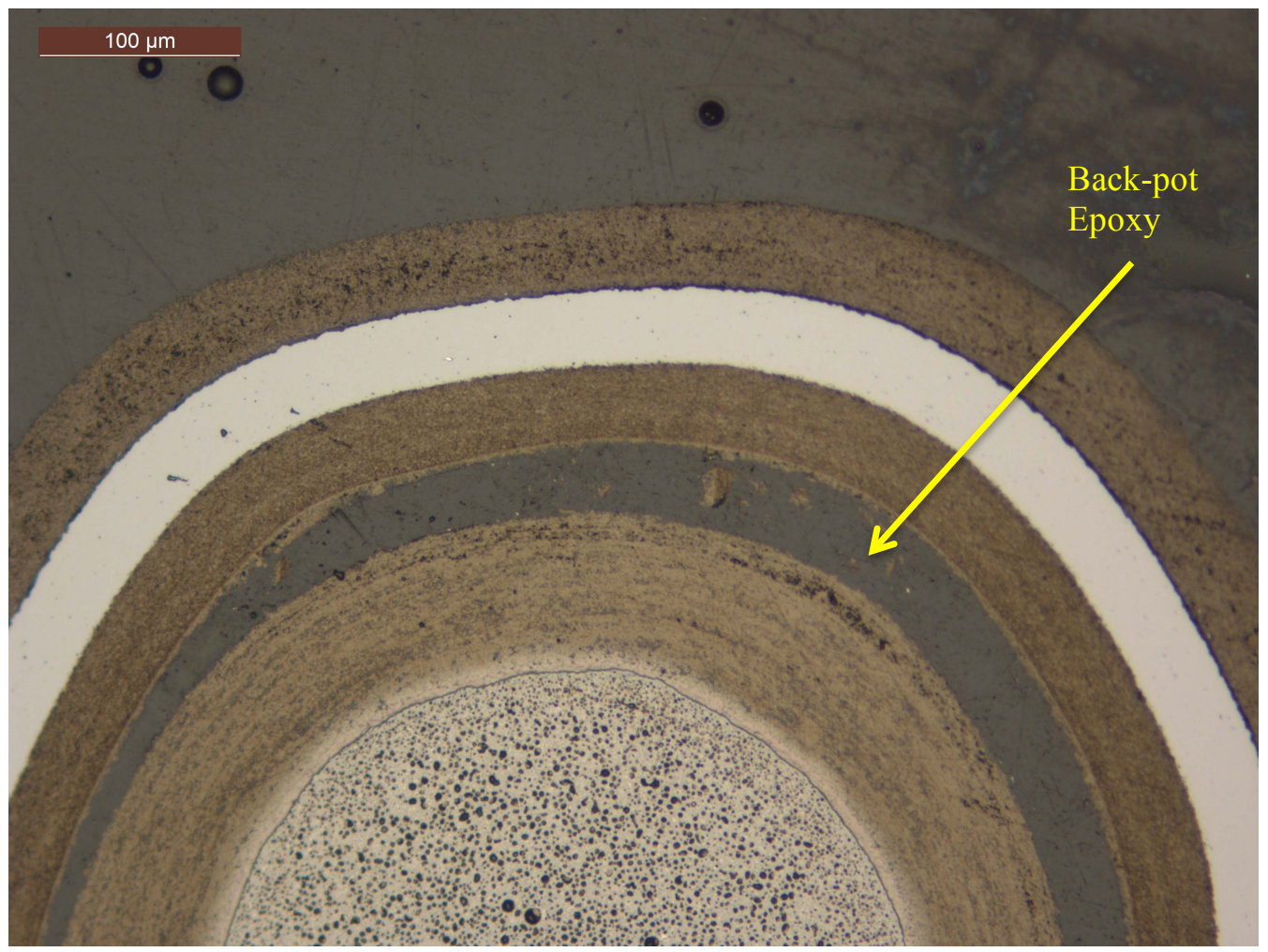

Figure 13. Optical micrograph of polished cross section of particle from Compact 6-1-1. 


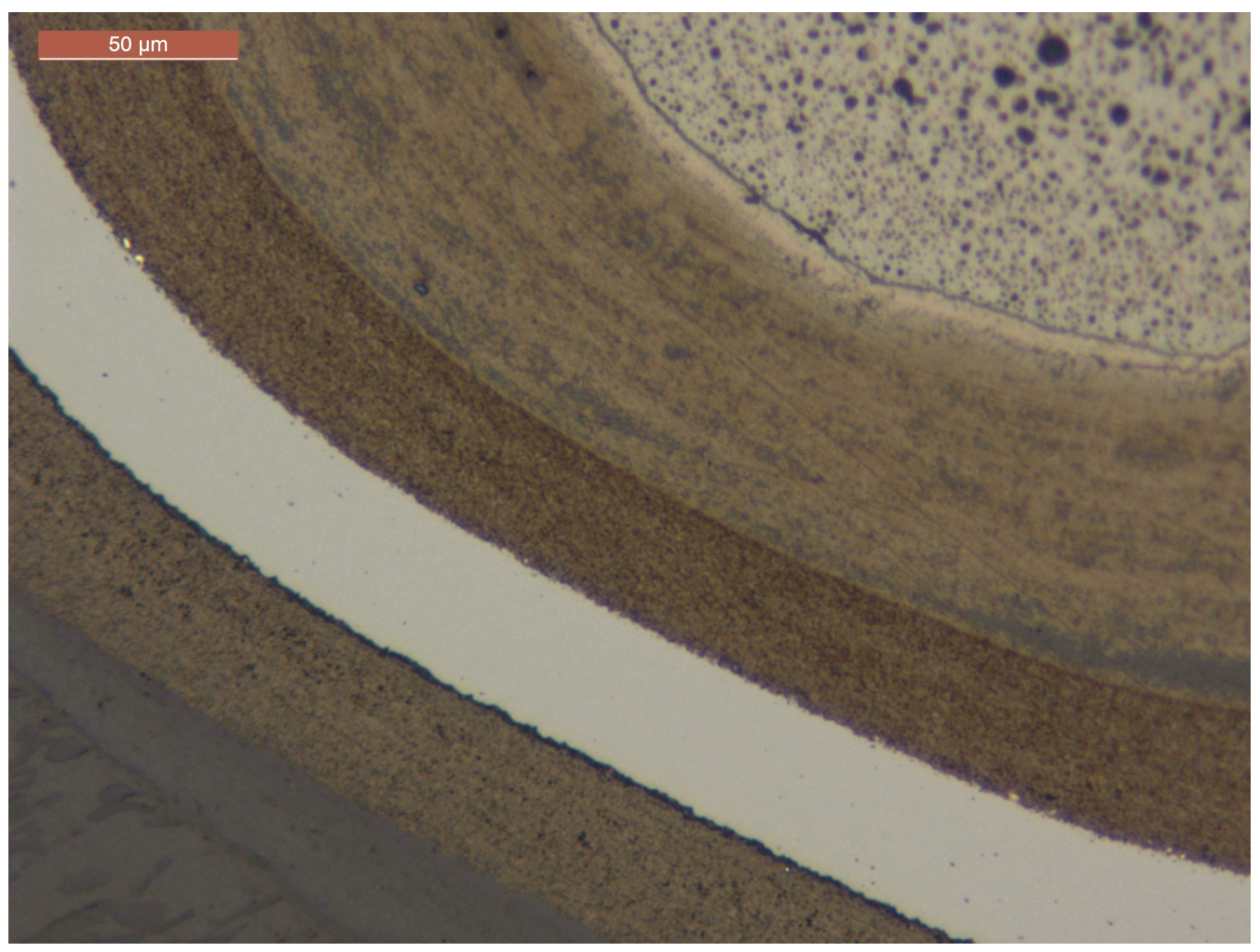

Figure 14. Optical micrograph of polished cross section of particle from Compact 6-1-1.

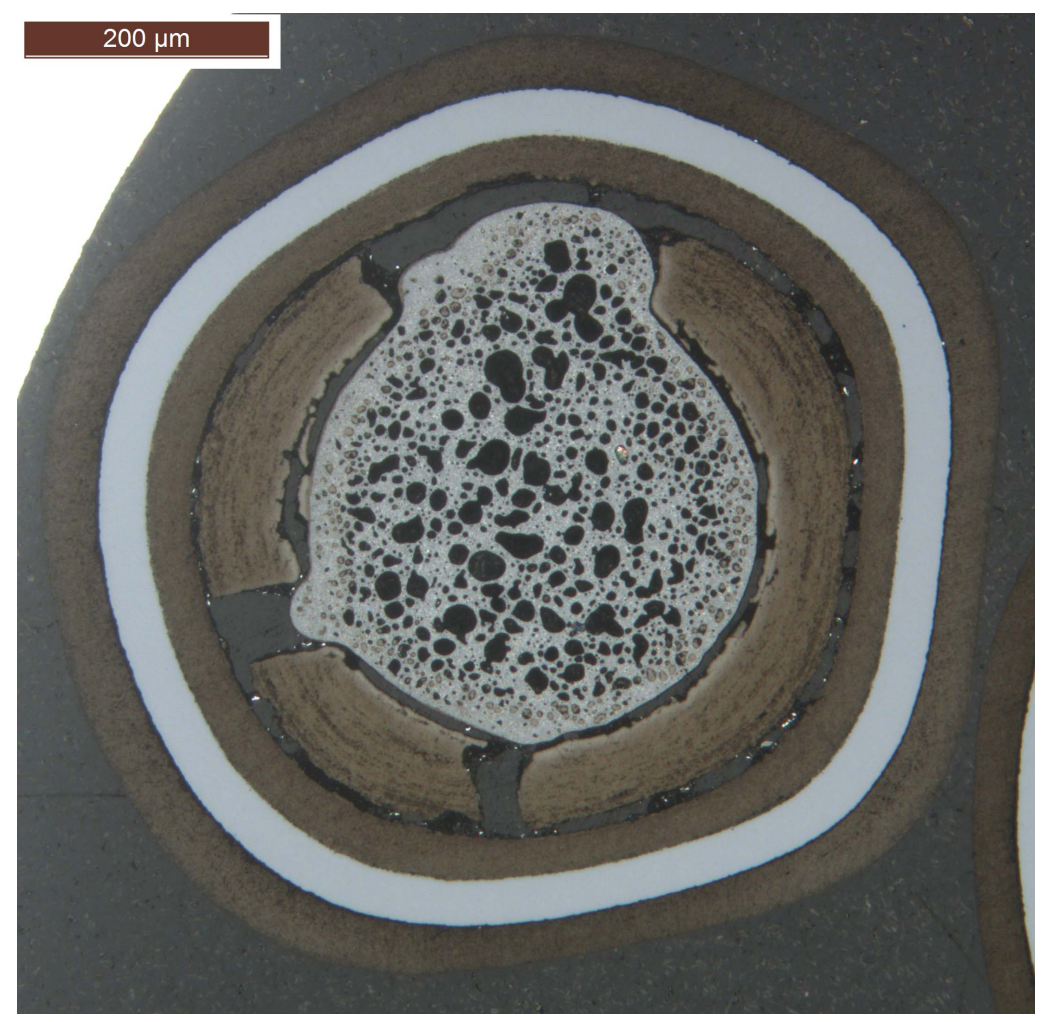

Figure 15. Optical micrograph of particle from Compact 5-2-3 with fractured buffer and protruding kernel. 


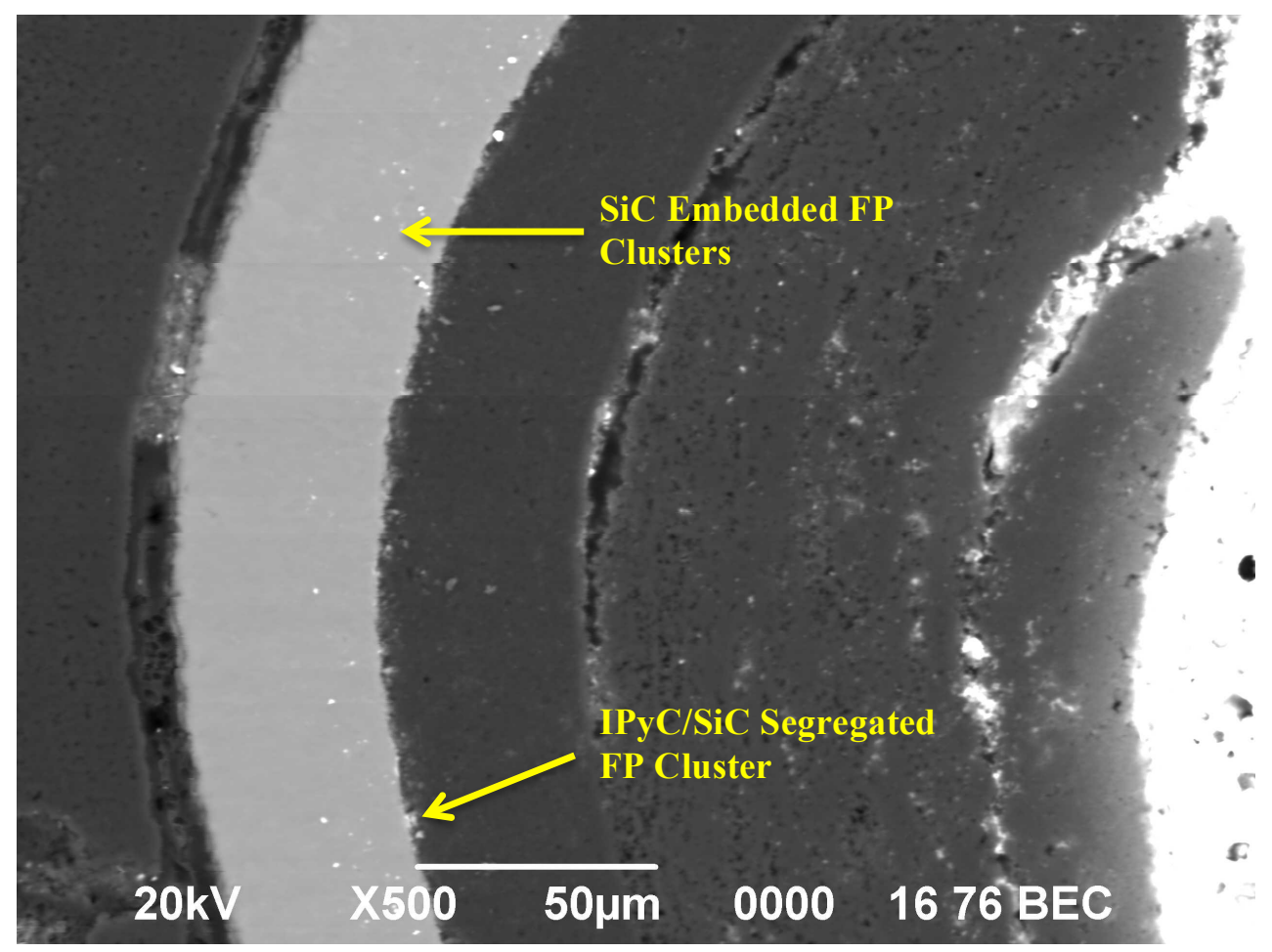

Figure 16. Back-scattered electron image of particle from Compact 6-1-1 showing fission product (FP) cluster at the inside surface and within the SiC.

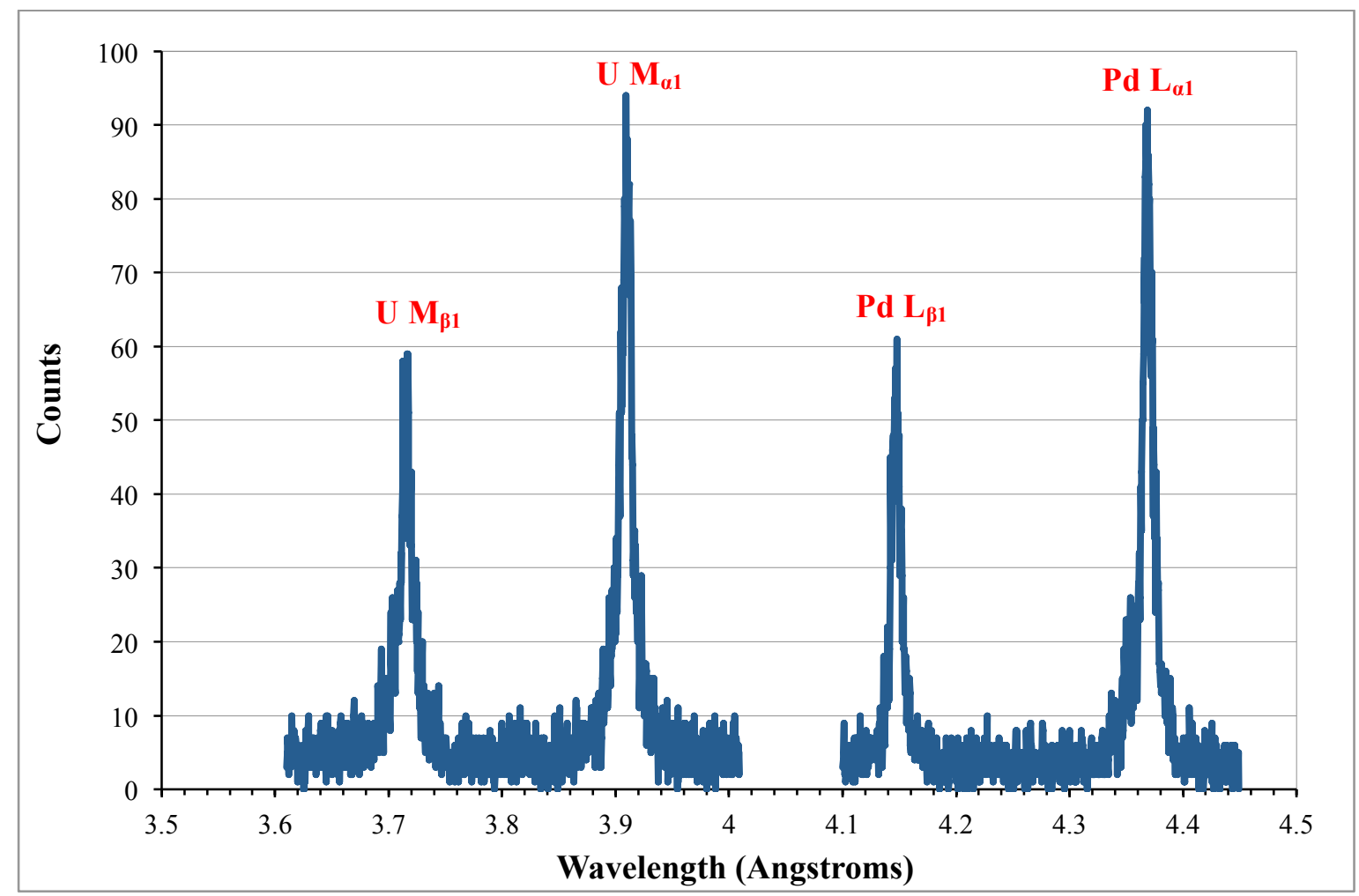

Figure 17. WDS wavescans indicating $P d$ and $U$ in a fission product cluster embedded in the SiC. 


\section{Results of Safety Testing at $1600^{\circ} \mathrm{C}$ and additional PIE on Two AGR-1 Compacts}

Compacts 6-4-3 and 3-3-2 (both AGR-1 Baseline fuel) were subjected to safety testing at $1600^{\circ} \mathrm{C}$ in flowing helium for 300-400 hours in the ORNL Core Conduction Cooldown Test Facility (CCCTF) to evaluate the effect of elevated temperature on the fuel microstructure and fission product retention. During the test period, condensable fission products (metals) were collected by the CCCTF in-furnace cold finger and gaseous fission products were collected from the helium sweep gas as it passed through liquid nitrogen-cooled cold traps. Deposition cups attached to the in-furnace cold finger were periodically removed and analyzed by gamma spectrometry and the sweep gas traps were constantly monitored for gamma activity throughout each run.

Overall, the coated particle fuel continued to retain fission products generated during the three-year irradiation test, as designed. No significant gaseous ${ }^{85} \mathrm{Kr}$ release was detected by the sweep gas analysis system. Krypton release would be indicative of failure of all three outer layers of the tristructural isotropic (TRISO) coating, and is the primary indicator for catastrophic particle failure during the heating test. However, some fission products were released from the compacts during the test. The main fission products detected on the deposition cups were silver and europium, with smaller amounts of strontium. Only trace amounts of cesium were released, except for Compact 3-3-2, where there was one particle with defective $\mathrm{SiC}$ that released virtually all its inventory of ${ }^{134} \mathrm{Cs}$ and ${ }^{137} \mathrm{Cs}$ to the deposition cup. This was the only defective particle detected in any of the CCCTF tests thus far, and post-test analysis determined that the release was related to an as-fabricated $\mathrm{SiC}$ defect. Although there was a through-wall defect in the $\mathrm{SiC}$, the particle did not release ${ }^{85} \mathrm{Kr}$, because one or more pyrocarbon layers remained intact.

After completion of the safety testing, acid leaching and additional analysis was performed on the deposition cups and CCCTF furnace internals (graphite fuel holder, tantalum furnace liner, and tantalum gas inlet line) to account for the entire inventory of fission products released from the compact and calculate an average deposition cup collection efficiency for each detectable fission product. This average collection efficiency was then used to calibrate the time-dependent deposition cup data to estimate the total time-dependent fission product release from each compact throughout the safety test. Additional post-safety test PIE was also performed on each compact using the standard analyses described above (DLBL, IMGA, x-ray tomography, and materialography).

\section{Compact 6-4-3 results}

Figure 18 shows the temperature profile and estimated time-dependent fission product releases from Compact 6-4-3. The plotted fractional release values are the cumulative amount of each fission product collected on the deposition cups, adjusted for radioactive decay and average collection efficiency, and divided by the predicted compact inventory for each fission product at the end of the irradiation. Silver was released from the compact as it was initially heated up, and no additional significant silver release was detected while the compact was held at $1600^{\circ} \mathrm{C}$ for 400 hours. The observed ${ }^{110 \mathrm{~m}} \mathrm{Ag}$ release was of the same order of magnitude as that observed in the DLBL analysis of the as-irradiated compacts (Table 1), and post-safety test DLBL (Table 2) measured a significantly smaller quantity. This suggests that the silver release observed at the beginning of the safety test came from silver outside the SiC, presumably released through intact $\mathrm{SiC}$ during irradiation. Also note that palladium, which was observed in the asirradiated compacts at relatively high levels, was not detected by DLBL after the safety test, indicating it may also have left the compact when it was heated to $1600^{\circ} \mathrm{C}$. Palladium is not detected by gamma spectrometry, and additional mass spectrometry will be require to detect it after the CCCTF test.

More europium and strontium remained in the compact than were released by the $1600^{\circ} \mathrm{C}$ safety test. It cannot be determined if any additional europium or strontium were released from the particles, but it is possible that they may just be migrating out of the compact matrix during the safety test, similar to what has been suggested for silver. Additional heating tests on individual particles would be useful for determining if these elements are retained by the particles under safety test conditions. 


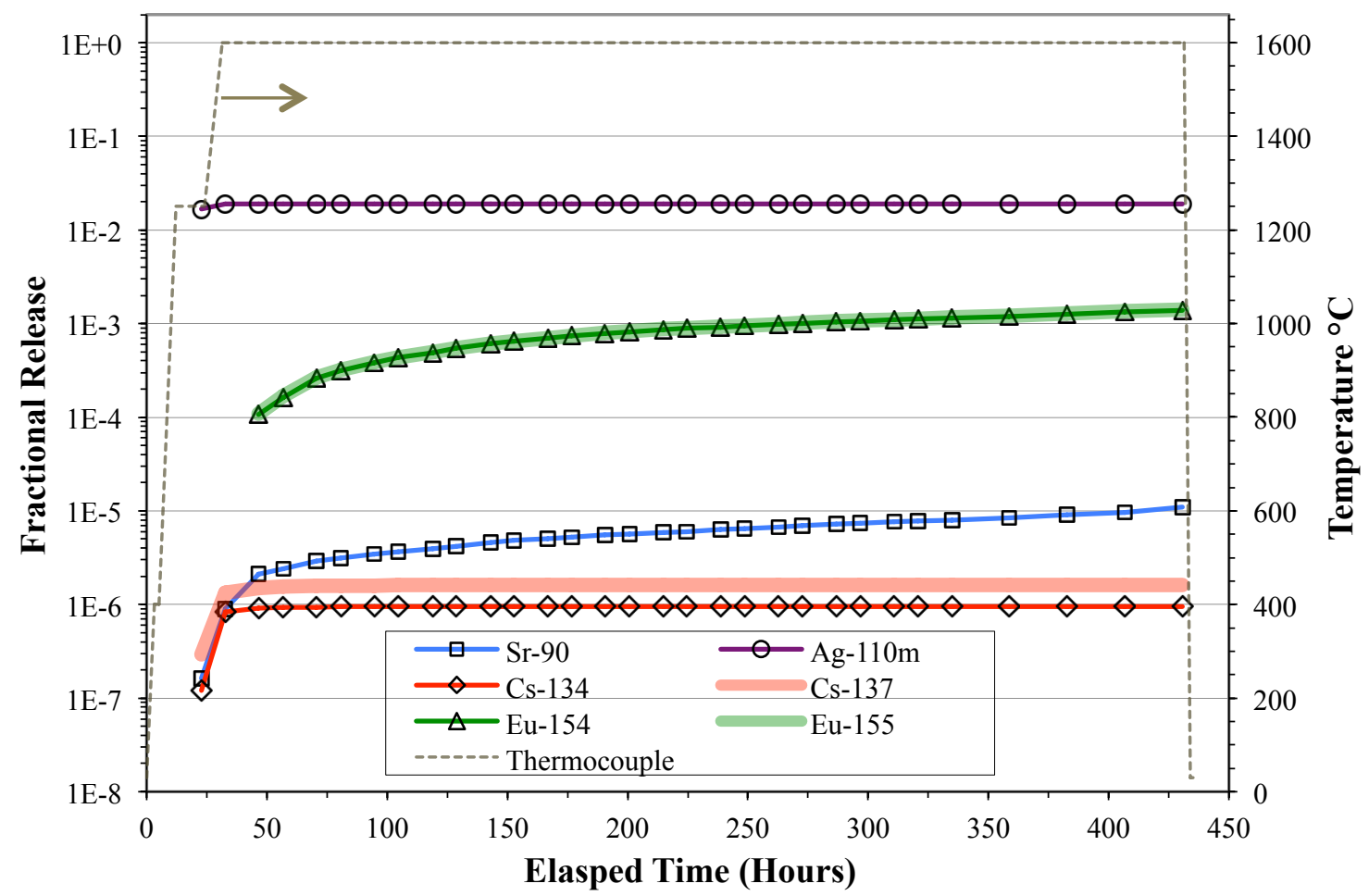

Figure 18. Release of fission products from Compact 6-4-3 during safety testing to $1600^{\circ} \mathrm{C}$.

Table 2. DLBL analysis results for Compact 6-4-3.

\begin{tabular}{|c|c|c|c|c|c|c|}
\hline \multirow{3}{*}{$\begin{array}{c}\text { Fission Product } \\
{ }^{90} \mathrm{Sr}\end{array}$} & \multicolumn{6}{|c|}{ Compact 6-4-3 } \\
\hline & \multicolumn{2}{|c|}{ pre-burn } & \multicolumn{2}{|c|}{ post burn } & \multicolumn{2}{|c|}{ total } \\
\hline & $3.8 \mathrm{E}-$ & $(0.02)$ & $1.4 \mathrm{E}-5$ & $(0.05)$ & $1.8 \mathrm{E}-5$ & $(0.07)$ \\
\hline${ }^{105} \mathrm{Pd}$ & \multicolumn{2}{|c|}{ n.d. } & \multicolumn{2}{|c|}{ n.d. } & \multicolumn{2}{|c|}{ n.d. } \\
\hline${ }^{110 \mathrm{~m}} \mathrm{Ag}$ & \multicolumn{2}{|c|}{ n.d. } & $5.8 \mathrm{E}-4$ & (2.4) & $5.8 \mathrm{E}-4$ & $(2.4)$ \\
\hline${ }^{134} \mathrm{Cs}$ & $1.1 \mathrm{E}-\mathrm{C}$ & $(0.005)$ & $2.1 \mathrm{E}-6$ & $(0.008)$ & $3.2 \mathrm{E}-6$ & $(.01)$ \\
\hline${ }^{137} \mathrm{Cs}$ & $2.3 \mathrm{E}-\mathrm{C}$ & $(0.01)$ & $1.8 \mathrm{E}-5$ & $(0.07)$ & $2.0 \mathrm{E}-5$ & $(0.08)$ \\
\hline${ }^{144} \mathrm{Ce}$ & $1.9 \mathrm{E}-\mathrm{C}$ & $(0.008)$ & $6.2 \mathrm{E}-6$ & $(0.03)$ & $8.1 \mathrm{E}-6$ & $(0.04)$ \\
\hline${ }^{152} \mathrm{Sm}$ & $2.1 \mathrm{E}-$ & $(0.85)$ & $9.2 \mathrm{E}-4$ & (3.8) & $1.1 \mathrm{E}-3$ & $(4.7)$ \\
\hline${ }^{154} \mathrm{Eu}$ & $7.0 \mathrm{E}-$ & $(2.9)$ & $1.3 \mathrm{E}-3$ & $(5.2)$ & $2.0 \mathrm{E}-3$ & (8.1) \\
\hline${ }^{155} \mathrm{Eu}$ & $6.2 \mathrm{E}-$ & (2.6) & $1.2 \mathrm{E}-3$ & (4.9) & $1.8 \mathrm{E}-3$ & $(7.5)$ \\
\hline${ }^{235} \mathrm{U}$ & $1.6 \mathrm{E}-$ & $(0.006)$ & $9.8 \mathrm{E}-6$ & $(0.04)$ & $1.1 \mathrm{E}-5$ & $(0.05)$ \\
\hline${ }^{239} \mathrm{Pu}$ & $4.1 \mathrm{E}-\mathrm{C}$ & $(0.02)$ & $3.2 \mathrm{E}-5$ & $(0.13)$ & $3.6 \mathrm{E}-5$ & $(0.15)$ \\
\hline
\end{tabular}

Release values are reported as the fraction of compact inventory and the equivalent number of exposed kernels (in parentheses). "n.d." indicates a value was not determined because the measure values were below the detection threshold. 
Migration of europium and strontium to the cold finger was slow, and it is likely that their time-dependent release shown in Figure 18 was a function of the migration kinetics, as opposed to time dependent release from the compact. Table 3 shows that these fission products were held up in the CCCTF graphite holder and tantalum furnace liner, whereas silver readily condensed on the water-cooled deposition cups.

Table 3: Distribution of released fission products detected in the CCCTF furnace internals.

\begin{tabular}{|c||c|c|c|c|}
\hline Component & ${ }^{\mathbf{1 1 0 m}^{\mathbf{A g}}}$ & ${ }^{\mathbf{1 5 4}} \mathbf{E u}$ & ${ }^{{ }^{155}} \mathbf{E u}$ & ${ }^{\mathbf{9 0}} \mathbf{S r}$ \\
\hline \hline Deposition Cups & $99.9 \%$ & $11 \%$ & $12 \%$ & $45 \%$ \\
\hline Tantalum Parts & $0.1 \%$ & $42 \%$ & $37 \%$ & $27 \%$ \\
\hline Graphite & $0.0 \%$ & $47 \%$ & $51 \%$ & $28 \%$ \\
\hline
\end{tabular}

Cesium release at $1600^{\circ} \mathrm{C}$ was low. Four hour IMGA analysis of 120 particles from Compact 6-4-3 (Figure 19) showed that the ${ }^{137} \mathrm{Cs}$ distribution was little changed from that observed for as-irradiated compacts (Figure 2). Silver retention in the particles was broadly distributed with a small population that had lost almost all their silver (Figure 20), but these results were similar to as-irradiated compacts and it cannot be concluded that the distribution is a result of the safety test. The main peak in the silver distribution was centered around a ratio of 0.8 measured versus calculated inventory, which is lower than observed for most compacts; the reason for this is not understood, but the shift is too large to explain by the amount of silver released in the safety test.

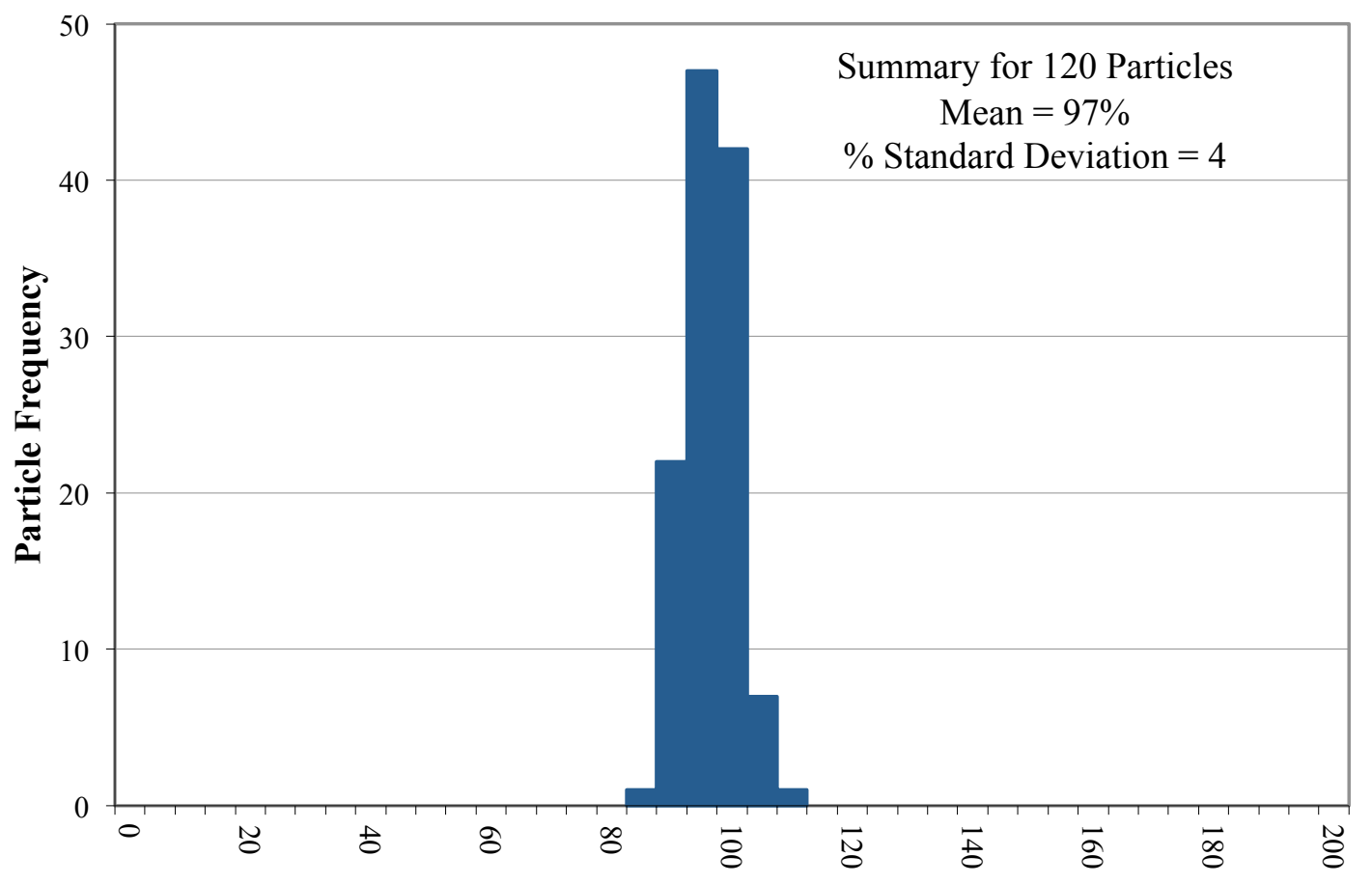

Estimated Percent Retention of Cs-137

Figure 19. Estimated fraction of ${ }^{137} \mathrm{Cs}$ retained in particles from Compact 6-4-3 based on calculated inventory and adjusted for variation in fissionable material and burn-up using the measured ${ }^{144} \mathrm{Ce}$ activity. 


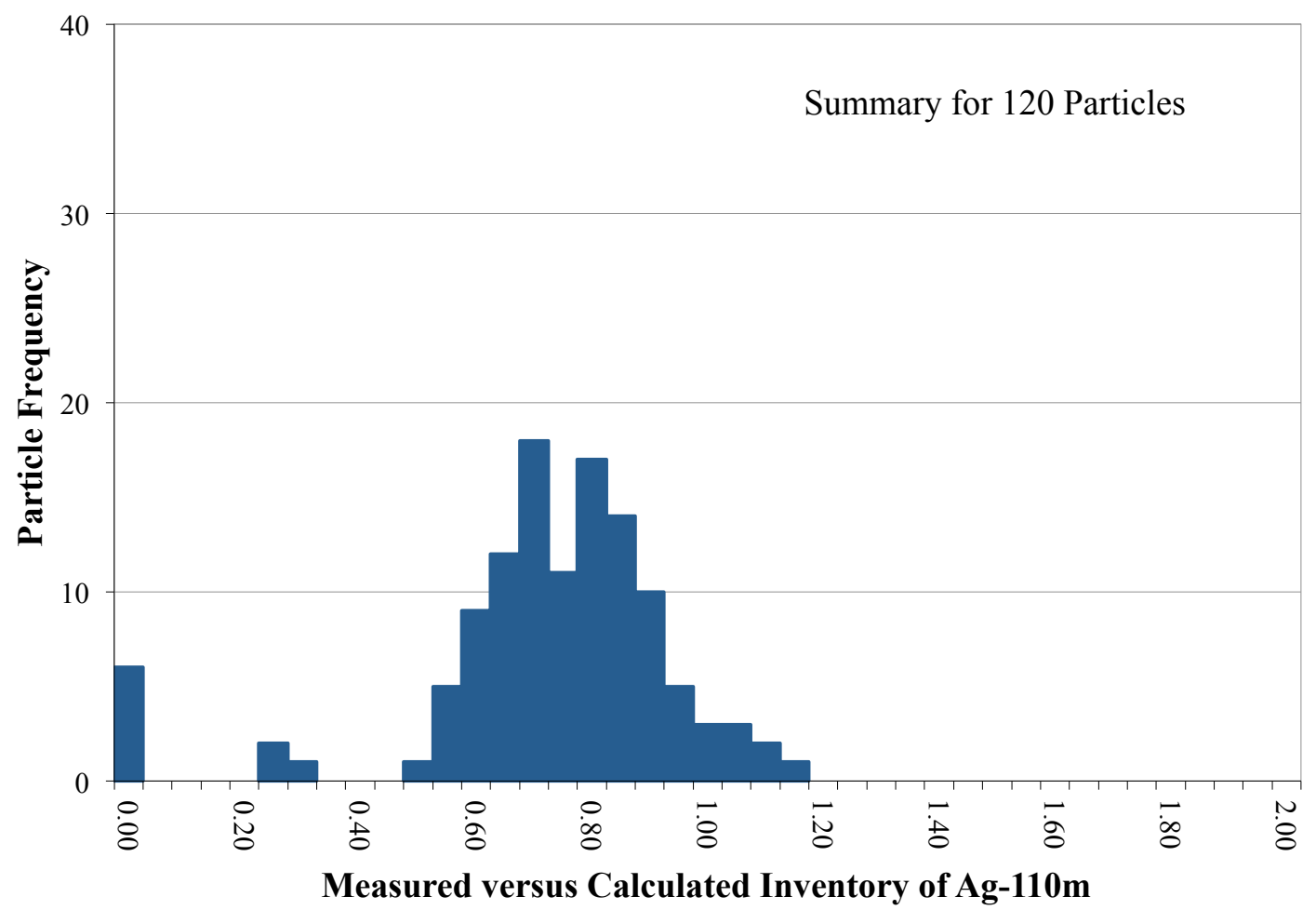

Figure 20. Ratio of ${ }^{110 \mathrm{~m}} \mathrm{Ag}$ retained in 120 particles from Compact 6-4-3 versus calculated inventory, adjusted for variation in fissile material and burnup using the ${ }^{137}$ Cs activity.

The six particles with ${ }^{110 \mathrm{~m}} \mathrm{Ag}$ content below the detection limit of the 4-hour IMGA scan, were analyzed by $\mathrm{x}$-ray tomography or materialography (three particles each) and compared to six other particles with higher silver retention. There was no apparent correlation between the particle microstructure and the silver retention, and the observed microstructure was similar to that observed on as-irradiated particles. Figure 21 shows two $\mathrm{x}$-ray tomography examples, one with typical buffer/IPyC separation, and one with cracks in the buffer and IPyC layers. The cracked inner layers have been observed in particles from other compacts and appear to occur more often when the buffer and IPyC layers do not separate.

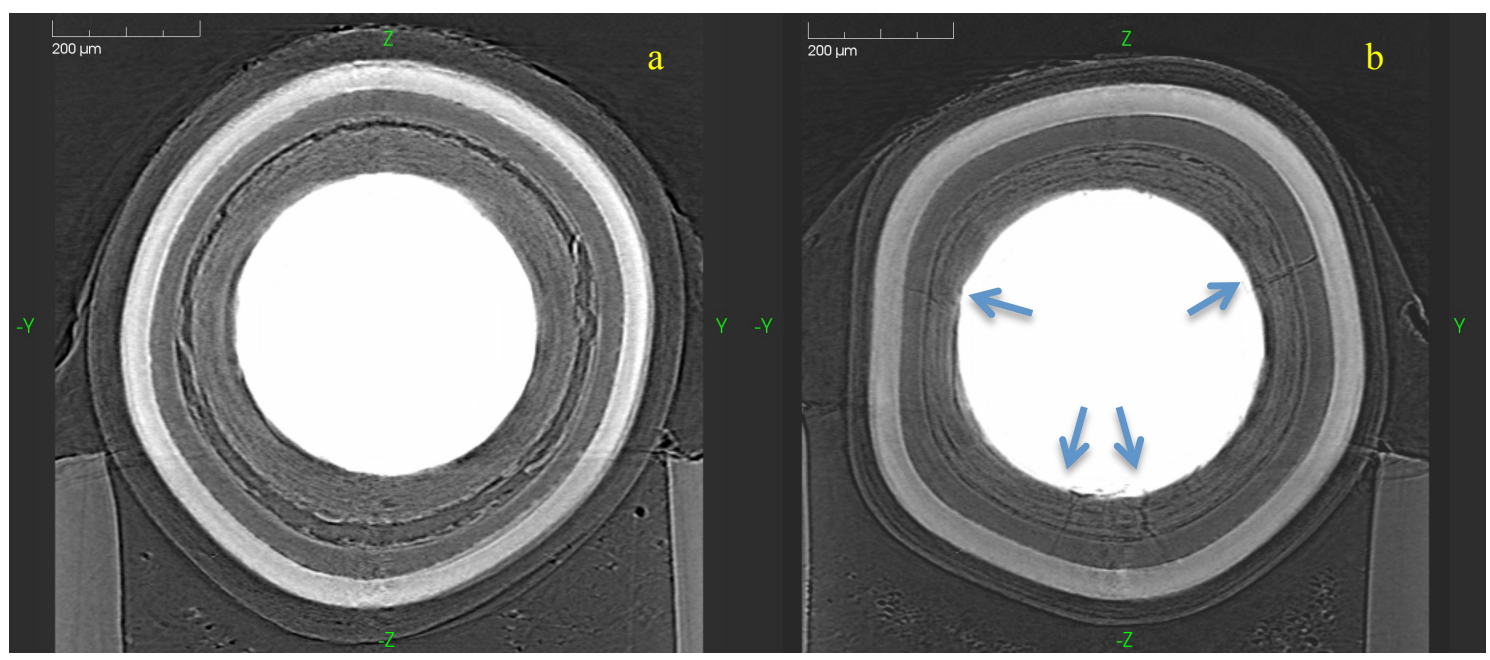

Figure 21. X-ray tomographs of a typical particle (a), and a particle with unusual cracks in the buffer and IPyC layers (b). Both of these particles exhibited normal silver retention. 
SEM/WDS analysis of mechanically polished cross sections was used to observe fission product clustering outside of the kernel. Results were similar to those obtained from the SEM analysis of Compact 6-1-1, but it was also noticed in these finer polished specimens that the Pd-U fission product clusters inside the $\mathrm{SiC}$ layer, evident as bright spots in Figure 22, could be observed further from the IPyC interface for those particles that released more silver. Further study of the fission product distribution within the $\mathrm{SiC}$ is needed to verify this result.
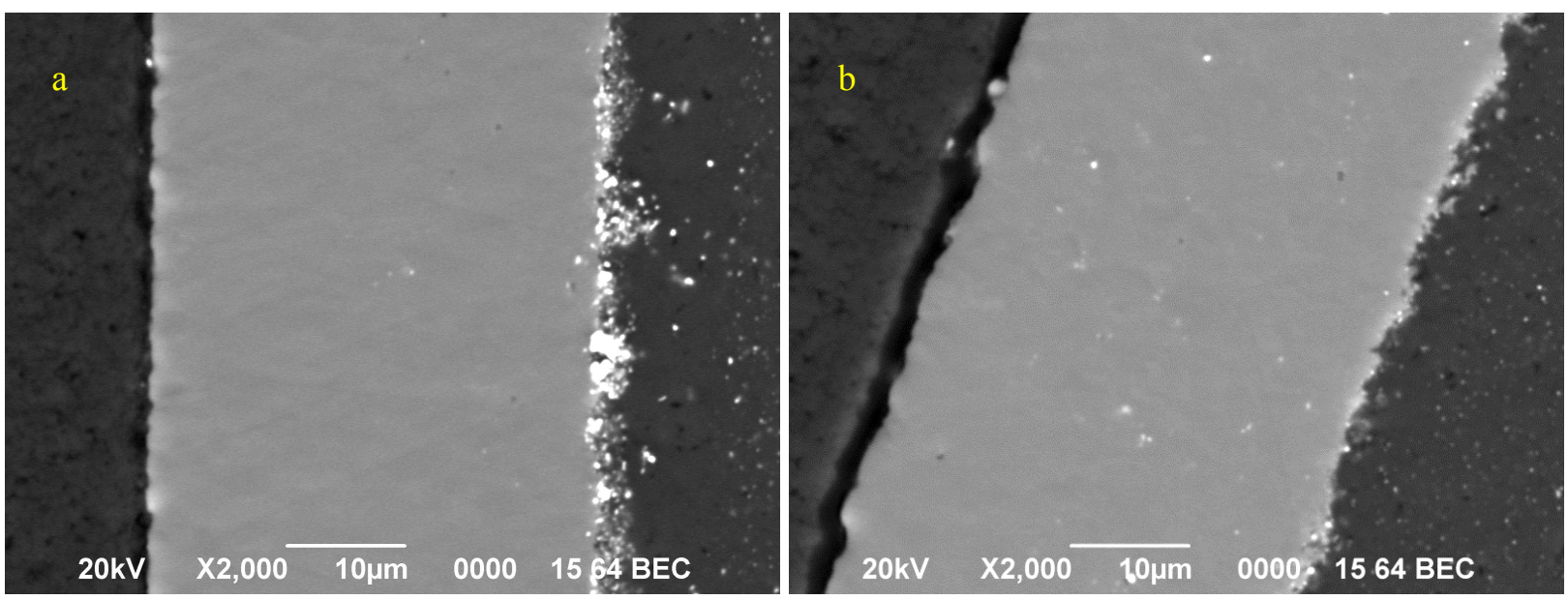

Figure 22. Back-scattered electron images of particle from Compact 6-4-3 with average ${ }^{110 \mathrm{~m}} \mathrm{Ag}$ retention (a) and ${ }^{110 \mathrm{~m}} \mathrm{Ag}$ retention below the detection limit (b). Bright spots indicate fission product clusters.

\section{Compact 3-3-2 results}

Figure 23 shows the temperature profile and estimated time-dependent fission product releases from Compact 3-3-2; this safety test was unusual because of the thermal cycling evident in the plotted temperature profile. At the beginning of the test, a power supply problem caused the circuit breaker to shut off power in response to an overcurrent condition. The test was restarted and the compact was heated to $1600^{\circ} \mathrm{C}$. After removal of the fourth deposition cup, the cold finger jammed and the furnace had to be shutdown until the problem could be corrected. As the compact was being reheated after the cold finger jam, the intermittent power supply failure reoccurred. One interesting result of the inadvertent thermal cycling was that additional silver appeared to be released as a result. In order to better investigate this effect, two additional temperature cycles were intentionally added to the end of the run.

Table 4 lists the total release for each detected fission product. The amount of cesium released from the compact was approximately equivalent to the cesium expected to be contained in a single particle. Cesium release during a safety test is normally very low (such as that shown in Figure 18), and any measurable release is typically related to a through-wall defect or failure of the $\mathrm{SiC}$ layer. After completion of the safety test, Compact 3-3-2 was electrolytically deconsolidated to recover the individual TRISO particles. Each of the 4137 particles was surveyed using the IMGA to detect any particle with unusually low cesium content. One particle was identified with less than $40 \%$ of the expected cesium. This particle was imaged using X-ray tomography (Figure 24), and the SiC layer was determined to be deformed and porous. This type of defect occurs during fabrication when a particle is over-fluidized, causing it to pick up carbon soot on the surface of the IPyC prior to $\mathrm{SiC}$ deposition. The fact that no ${ }^{85} \mathrm{Kr}$ was detected during the CCCTF test indicates that one or both of the pyrocarbon layers on this particle remained intact; no cracks in the pyrocarbon layers were evident in the $\mathrm{x}$-ray imaging. 


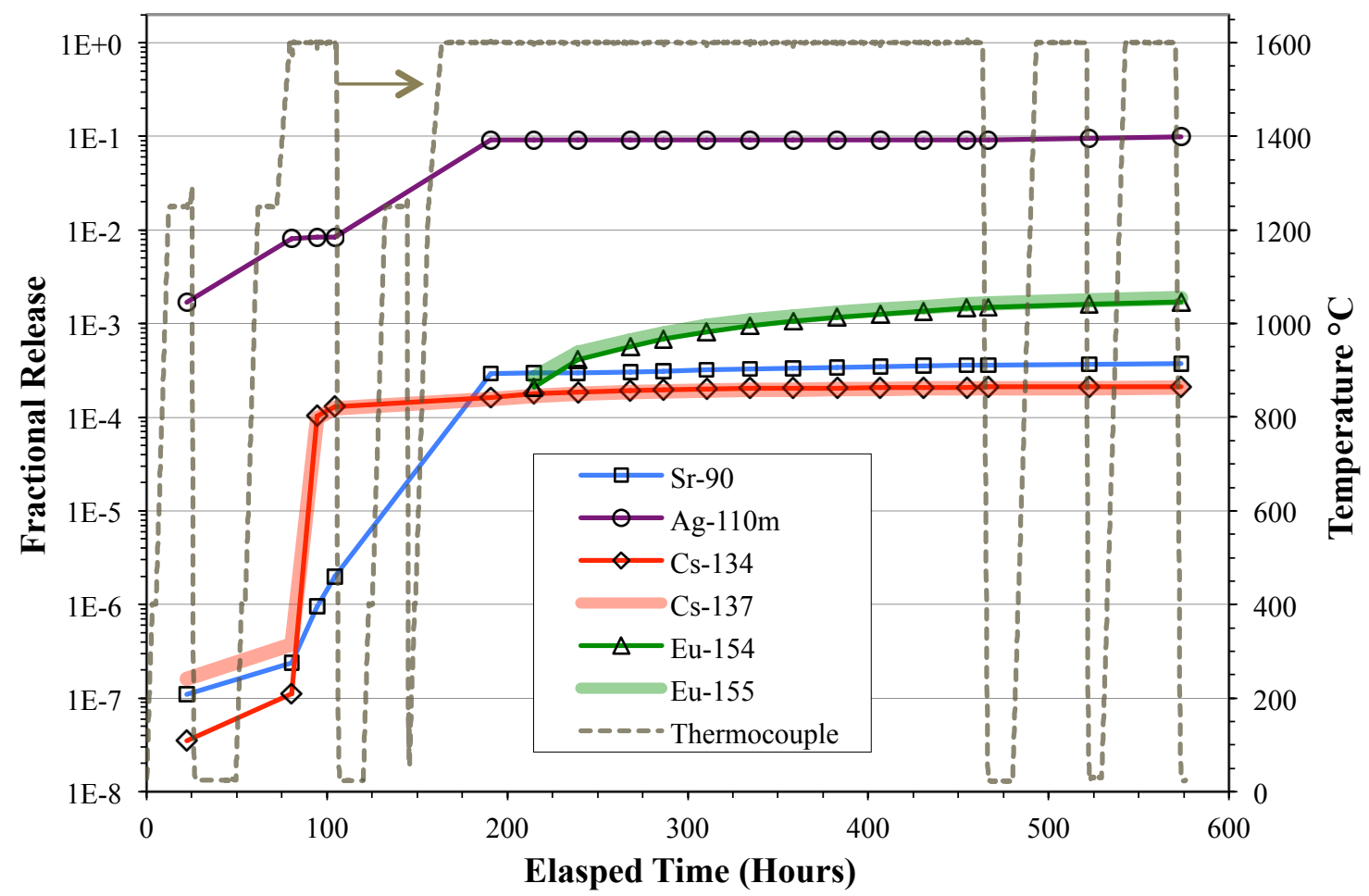

Figure 23. Release of fission products from Compact 3-3-2 during safety testing to $1600^{\circ} \mathrm{C}$.

Table 4. Cumulative fission product release from Compact 3-3-2 safety test

\begin{tabular}{|c||c|c|}
\hline Isotope & $\begin{array}{c}\text { Fraction of Calculated } \\
\text { Compact Inventory Released }\end{array}$ & $\begin{array}{c}\text { Equivalent Particle } \\
\text { Inventory }\end{array}$ \\
\hline \hline${ }^{85} \mathrm{Kr}$ & $<1 \mathrm{E}-06$ & $<4 \mathrm{E}-03$ \\
\hline${ }^{90} \mathrm{Sr}$ & $3.71 \mathrm{E}-04$ & 1.5 \\
${ }^{110 \mathrm{~m}} \mathrm{Ag}$ & $9.91 \mathrm{E}-02$ & 411 \\
\hline${ }^{134} \mathrm{Cs}$ & $2.12 \mathrm{E}-04$ & 0.88 \\
\hline${ }^{137} \mathrm{Cs}$ & $2.07 \mathrm{E}-04$ & 0.86 \\
\hline${ }^{154} \mathrm{Eu}$ & $1.72 \mathrm{E}-03$ & 7.1 \\
\hline${ }^{155} \mathrm{Eu}$ & $1.87 \mathrm{E}-03$ & 7.8 \\
\hline
\end{tabular}

Note: One particle is equivalent to a compact inventory fraction of $2.4 \times 10^{-4}$. 

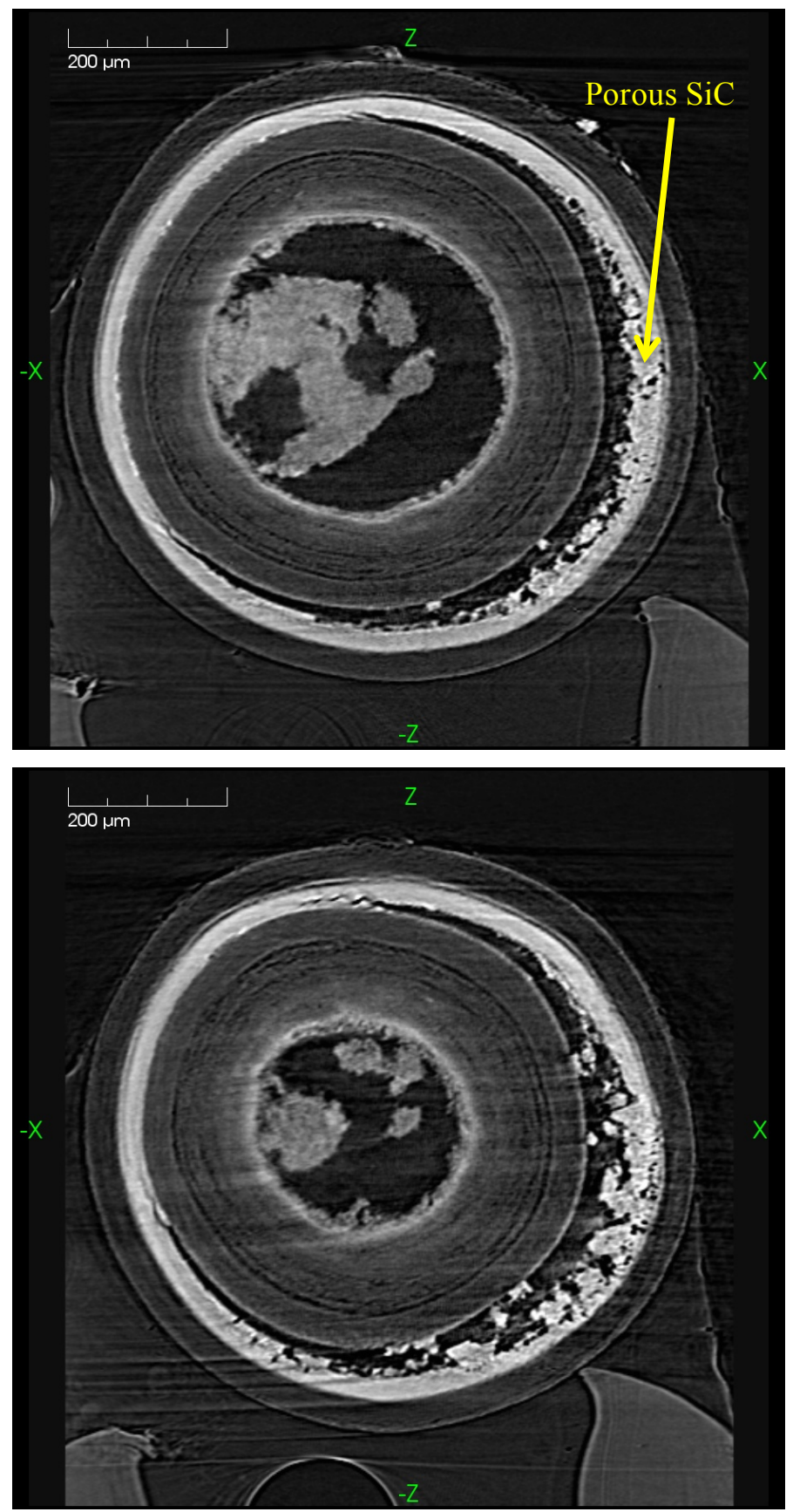

Figure 24. Two x-ray tomographs of two parallel planes through the abnormal particle from Compact 3-3-2.

After completion of $x$-ray imaging, the particle shown in Figure 24 was placed in a materialography mount and ground down to reveal the defective region. Figure 25 and Figure 26 show a polished cross section through the particle. A crack can be seen in the SiC layer that probably occurred when the particle was heated to $1600^{\circ} \mathrm{C}$ during the post-irradiation safety test, resulting in cesium release. The fact that negligible cesium was detected on the Capsule 3 components indicates that the defective $\mathrm{SiC}$ remained intact until after the irradiation test, in contrast to the behavior of the defective particles in Compact 5-2-3. 


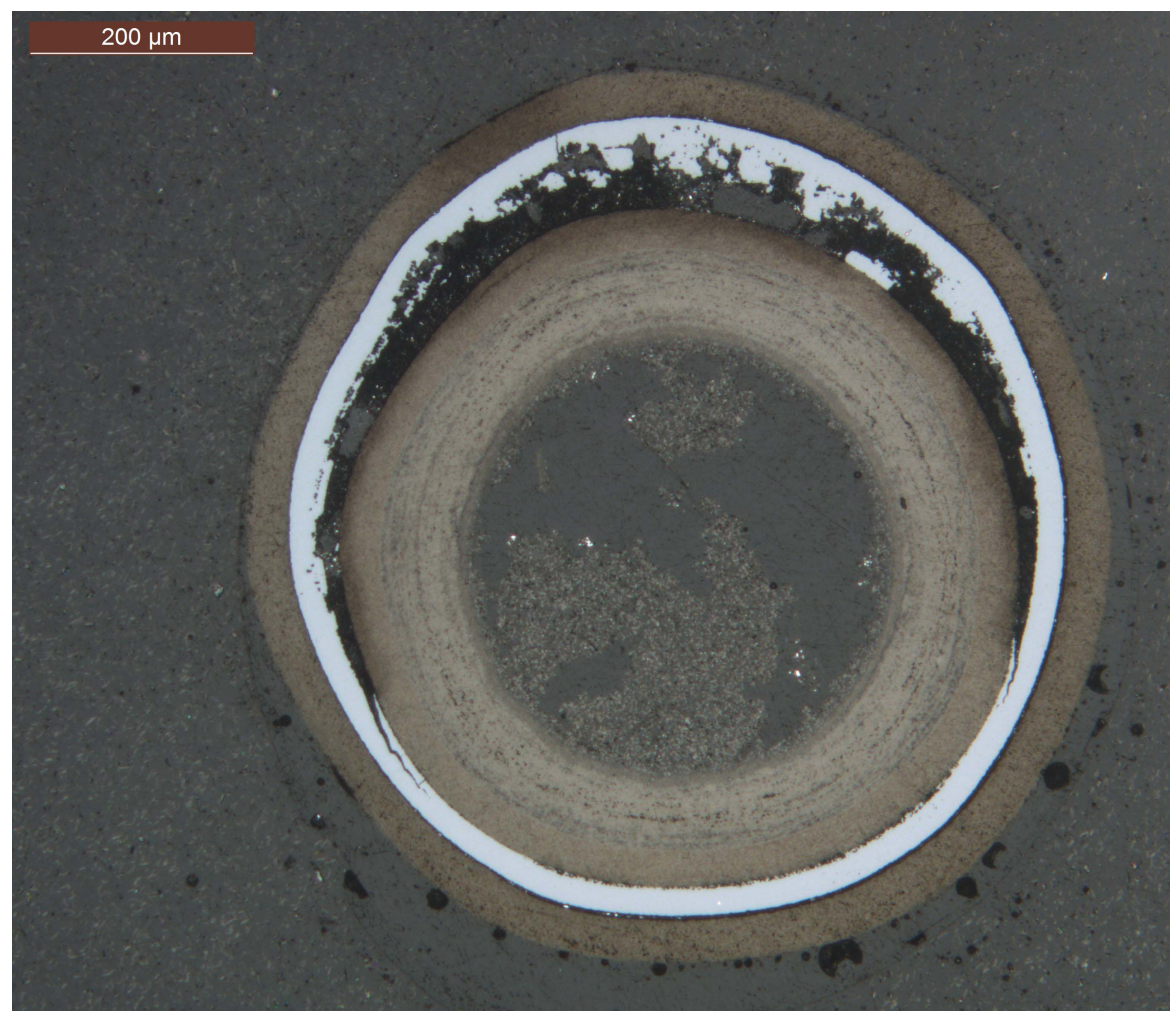

Figure 25. Optical micrograph of a polished cross section of the abnormal particle from AGR-1 Compact 3-3-2, prepared from specimen mounted for x-ray tomography (Figure 24).

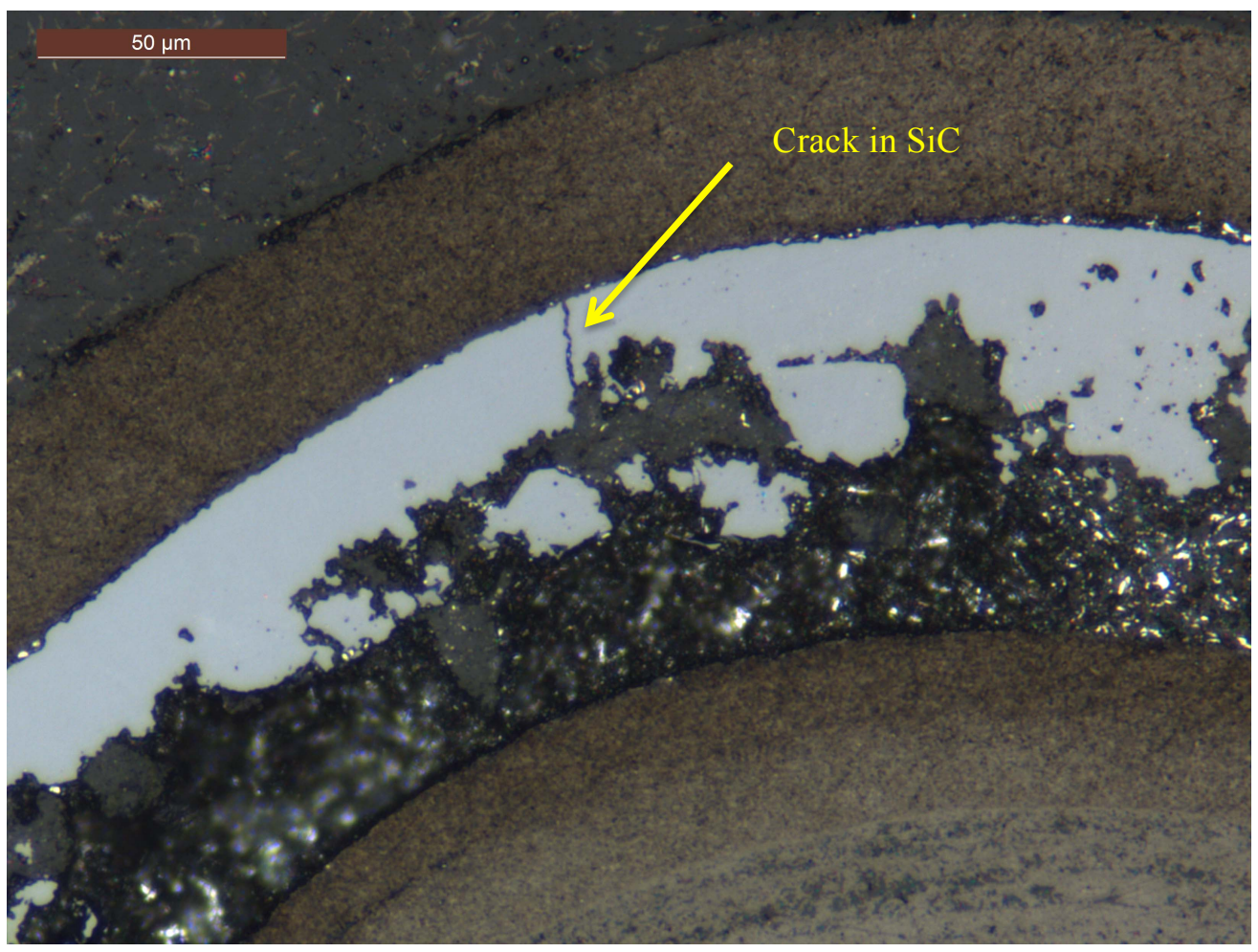

Figure 26. Higher resolution optical image of crack through $\mathrm{SiC}$ layer in abnormal particle from AGR-1 Compact 3-3-2. 
Of particular note was that silver release was detected each time Compact 3-3-2 was heated, but no significant silver release was detected while the compact was held at elevated temperature in between the thermal cycles. As mentioned above, two additional thermal cycles were added to the end of the run to further investigate this effect. The silver data is presented using a linear scale in Figure 27 to make the multiple silver release events more evident. Silver release dropped off after the initial rise to $1600^{\circ} \mathrm{C}$. After the run was interrupted by the cold finger jam at around 100 hours into the test, the compact was heated to $1300^{\circ} \mathrm{C}$, cooled, and then heated to $1600^{\circ} \mathrm{C}$. This resulted in a large spike in silver detected at the next deposition cup change. Constant exposure at $1600^{\circ} \mathrm{C}$ for almost 300 hours did not result in any additional significant silver collection. However, when the furnace was intentionally cooled and ramped back up to $1600^{\circ} \mathrm{C}$ two more times, more silver was released each time. At this point, it is not clear whether this unusual behavior is due to the temperature cycling or due to the local temperature gradients in the fuel and fuel holder driven by the changing temperature.

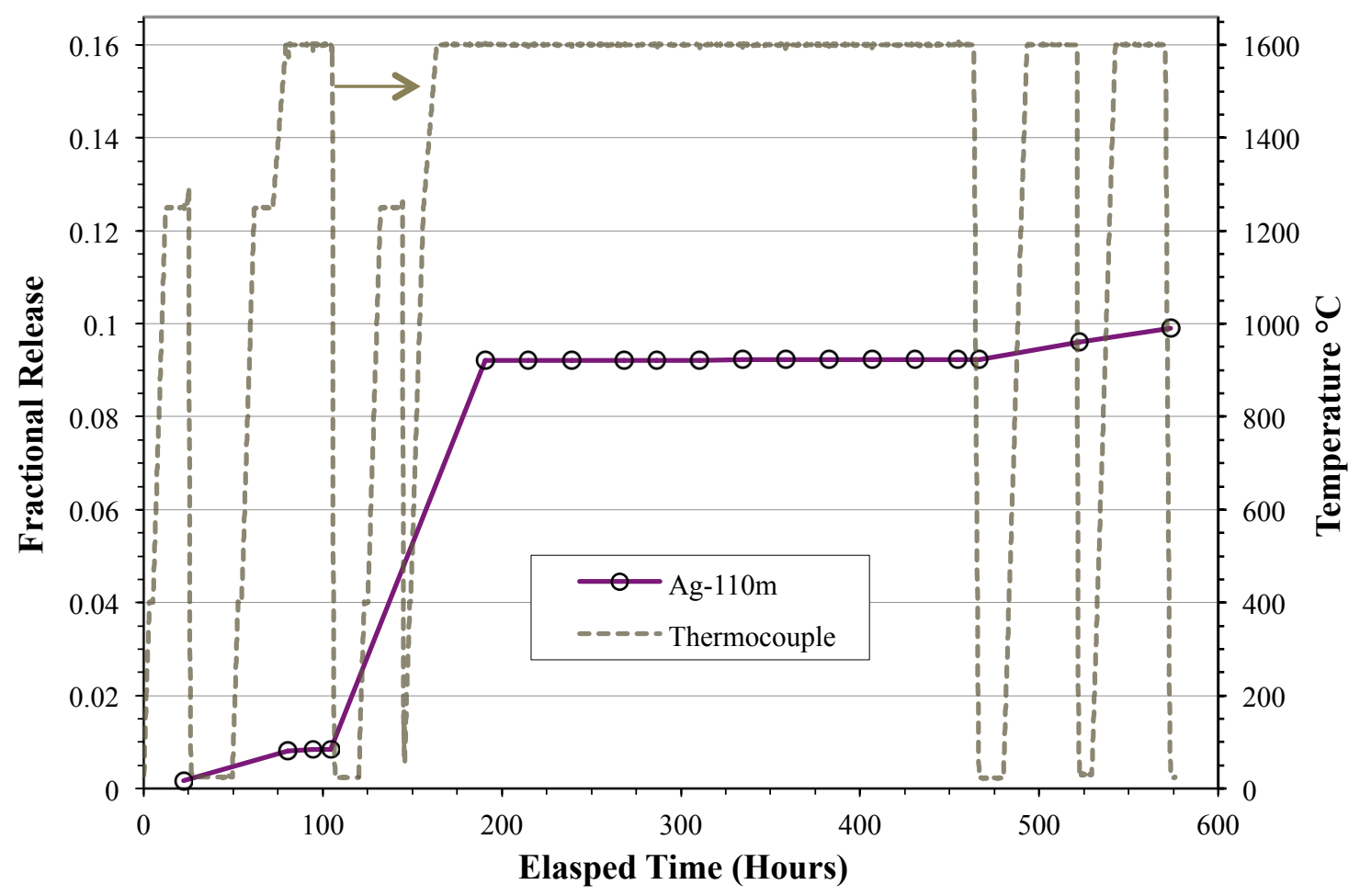

Figure 27. Silver release during AGR-1 Compact 3-3-2 heating test.

Table 5 shows the results of the DLBL analysis of Compact 3-3-2 after completion of the safety test. Similar to the results for Compact 6-4-3, the silver and palladium outside of the $\mathrm{SiC}$ was lower than observed for as-irradiated compacts, indicating loss during heating. A significant amount of U-235 was detected in the DLBL, coming from the matrix after the burn. The source of this uranium is still under investigation, including the possibility that it may be related to the unexplained reduced kernel mass observed in the defective particle (Figure 24 and Figure 25). This would imply that the uranium diffused out of the particle and into the matrix during the safety test, passing through intact pyrocarbon. Elemental analysis of the kernel residue will yield important information to support or rule out this possibility. If this is the source of the observed uranium, further tests could be performed to study the fission product retention capability of pyrocarbon layers in the absence of intact $\mathrm{SiC}$. 
Table 5. DLBL analysis results for Compact 3-3-2.

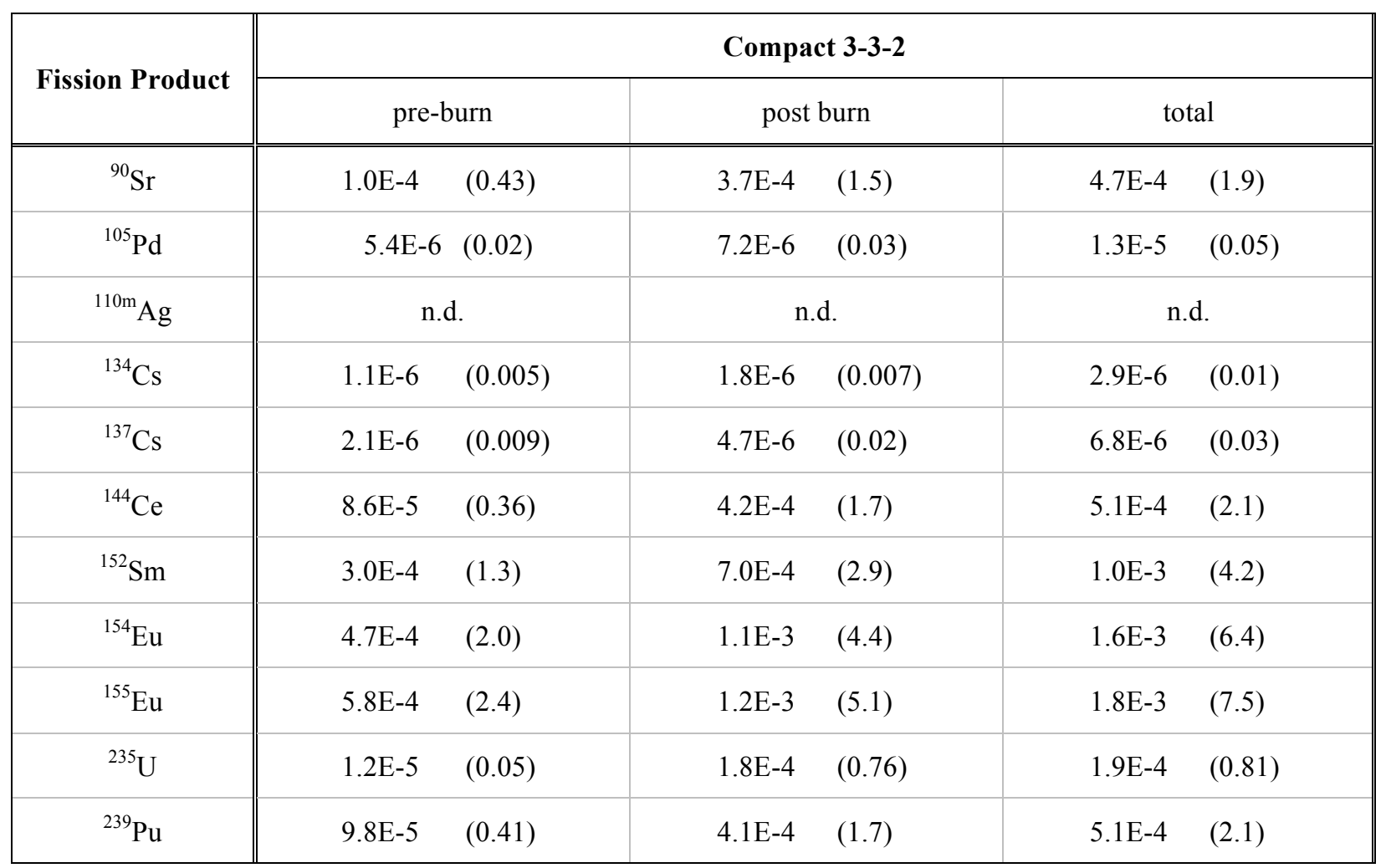

Release values are reported as the fraction of compact inventory and the equivalent number of exposed kernels (in parentheses). "n.d." indicates a value was not determined because the measure values were below the detection threshold.

In addition to the 100 second scan of each particle recovered from Compact 3-3-2 used to find the defective particle, 75 particles were riffled out for 5 hour scanning. Results were similar to the other compacts. Narrow distributions were observed for cerium, cesium, and europium. The distribution for ${ }^{110 \mathrm{~m}} \mathrm{Ag}$ was typically broad, with a peak centered around the calculated inventory and a small population of particles that retained less silver (Figure 28). As was done for other compacts, x-ray tomography and materialography were performed on particles selected from this set of 75 particles based on their silver inventory. Microstructure varied as has been seen for particles taken from other compacts, but no obvious correlation to silver retention was observed. Polished cross sections were prepared using conductive epoxy to support future planned SEM analysis to further study the possible role of palladium in silver migration through $\mathrm{SiC}$. 


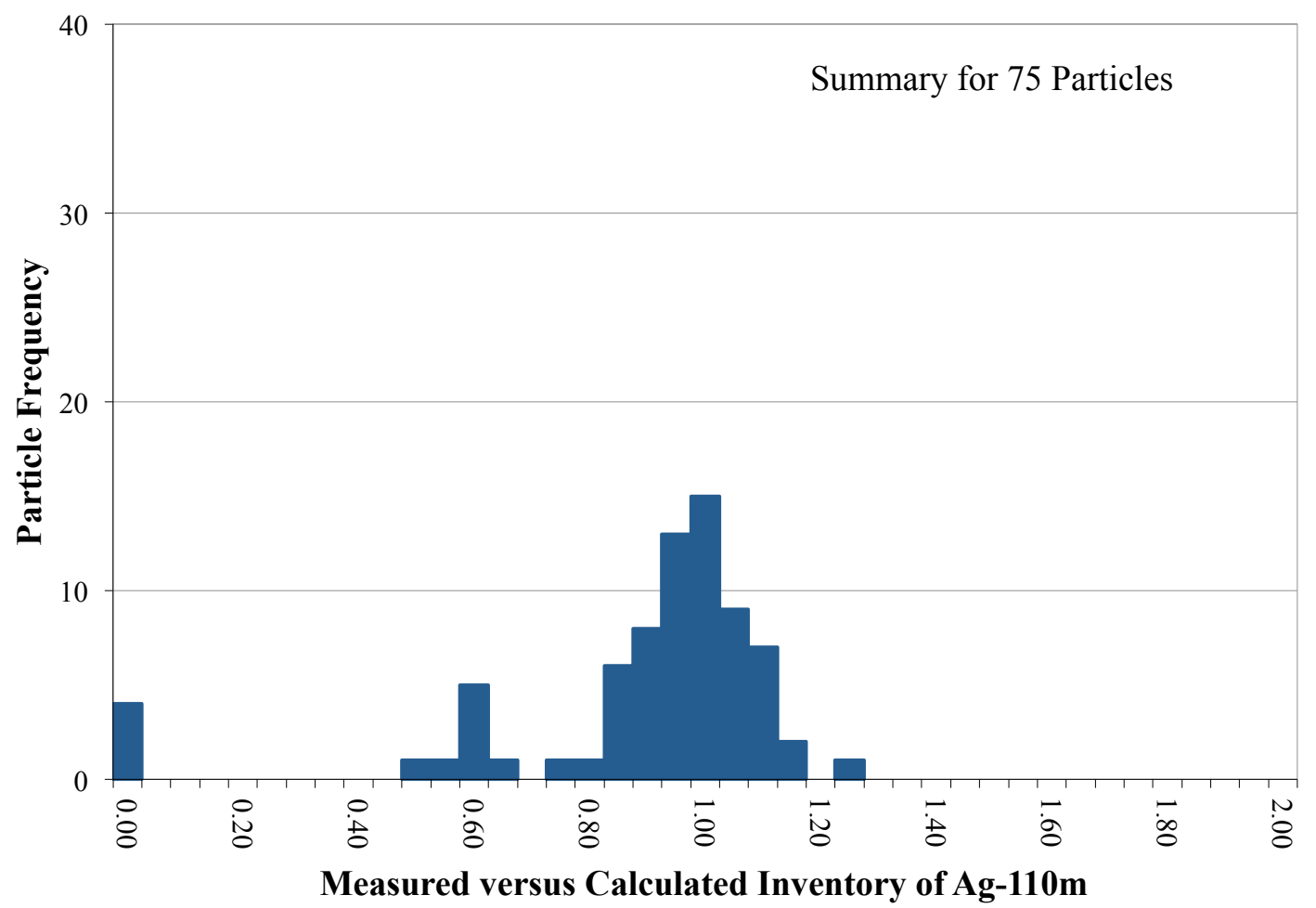

Figure 28. Ratio of ${ }^{110 \mathrm{~m}} \mathrm{Ag}$ retained in 75 particles from Compact 3-3-2 versus calculated inventory, adjusted for variation in fissile material and burnup using the ${ }^{137} \mathrm{Cs}$ activity.

\section{Conclusion}

Planned PIE was successfully carried out at ORNL on 5 compacts irradiated in the AGR-1 experiment using acid leaching, gamma spectroscopy, x-ray tomography, and materialographic methods. This PIE has provided new insights into TRISO particle fuel performance and suggested additional areas for future investigation. Data was obtained on fission product retention and radiation-induced microstructural changes. Cesium was generally well retained, making it a good indicator for particles with defective $\mathrm{SiC}$. These defective particles were efficiently detected using IMGA to survey all the particles in the compact, and x-ray tomography was very effective for interpreting these defects. Safety testing on two of the compacts demonstrated excellent fuel performance at $1600^{\circ} \mathrm{C}$. No $\mathrm{Kr}-85$ was released during the safety tests, and no negative effects from the elevated temperature were evident from the post-safety test PIE.

Some preliminary trends were suggested by the PIE results discussed in this report. Additional compacts from each lot need to be studied to verify some indications of performance variation between different fuel lots. DLBL results indicated a possible reduction of fission product release associated with the finer grain microstructure achieved using argon as a diluent during SiC deposition. This deposition process, used for AGR-1 Variant 3 fuel, is now the baseline process for AGR-2 and beyond.

The general mechanism for silver release, and the additional effect of thermal cycling need to be studied further. Thermal cycling could be an important factor in silver release during irradiation. X-ray tomography and mechanical cross sectioning, followed by analysis with optical and scanning electron microscopes, may help determine why silver retention varies, but thermal history may also play a key role. Furnace testing of individual particles using various thermal profiles would help provide additional understanding of the effect that maximum temperature and temperature gradient could have on silver retention. 
The possible role of palladium in silver migration through intact $\mathrm{SiC}$ requires further attention. Palladium release from intact $\mathrm{SiC}$ is higher than expected, and needs to be quantified better. Although significant palladium has been detected outside of the $\mathrm{SiC}$ and palladium has been observed clustered inside the $\mathrm{SiC}$, palladium corrosion has not been observed, with the possible exception of a few select particles.

In addition to silver and palladium, a minor release of other fission products is an area for further study. The possibility that small fractions of some lanthanides and actinides may diffuse through the layers, with higher releases for particles with through-wall $\mathrm{SiC}$ defects, could be better understood with further research. Some experiments involving unirradiated kernels coated with just buffer and IPyC would provide additional insight into the mechanisms by which uranium may be released through intact pyrocarbon. Data currently being obtained on fission product release needs to be analyzed in conjunction with thermochemical modeling to better understand the possible chemical forms and mobility of the various fission products.

\section{Acknowledgment}

This work was supported by the U.S. Department of Energy, Office of Nuclear Energy, under the Very High Temperature Reactor Technology Development Office/Advanced Gas Reactor Fuel Development and Qualification Program. 